\title{
Calcium Entry through Cyclic Nucleotide-Gated Channels in Individual Cilia of Olfactory Receptor Cells: Spatiotemporal Dynamics
}

\author{
Trese Leinders-Zufall,, ${ }^{1}$ Mark N. Rand, ${ }^{1}$ Gordon M. Shepherd, ${ }^{1}$ Charles A. Greer, ${ }^{1,2}$ and Frank Zufall ${ }^{1}$ \\ ${ }^{1}$ Section of Neurobiology and ${ }^{2}$ Department of Neurosurgery, Yale University School of Medicine, \\ New Haven, Connecticut 06510
}

\begin{abstract}
Transient elevations of intracellular $\mathrm{Ca}^{2+}$ play an important role in regulating the sensitivity of olfactory transduction, but such elevations have not been demonstrated in the olfactory cilia, which are the site of primary odor transduction. To begin to understand $\mathrm{Ca}^{2+}$ signaling in olfactory cilia, we used highresolution imaging techniques to study the $\mathrm{Ca}^{2+}$ transients that occur in salamander olfactory receptor neurons (ORNs) as a result of cyclic nucleotide-gated (CNG) channel activation. To visualize ciliary $\mathrm{Ca}^{2+}$ signals, we loaded ORNs with the $\mathrm{Ca}^{2+}$ indicator dye Fluo-3 AM and measured fluorescence with a laser scanning confocal microscope. Application of the phosphodiesterase inhibitor IBMX increased fluorescence in the cilia and other neuronal compartments; the ciliary signal occurred first and was more transient. This signal could be abolished by lowering external $\mathrm{Ca}^{2+}$ or by applying LY83583, a potent
\end{abstract}

blocker of CNG channels, indicating that $\mathrm{Ca}^{2+}$ entry through CNG channels was the primary source of fluorescence increases. Direct activation of CNG channels with low levels of 8-Br-cGMP $(1 \mu \mathrm{M})$ led to tonic $\mathrm{Ca}^{2+}$ signals that were restricted locally to the cilia and the dendritic knob. Elevated external $\mathrm{K}^{+}$, which depolarizes cell membranes, increased fluorescence signals in the cell body and dendrite but failed to increase ciliary $\mathrm{Ca}^{2+}$ fluorescence. The results demonstrate the existence and spatiotemporal properties of $\mathrm{Ca}^{2+}$ transients in individual olfactory cilia and implicate CNG channels as a major pathway for $\mathrm{Ca}^{2+}$ entry into ORN cilia during odor transduction.

Key words: olfactory receptor neurons; cilia; confocal microscopy; imaging; CAMP; cGMP; calcium signaling; cyclic nucleotide-gated channels; salamander; sensory adaptation; G-protein-coupled second messenger pathways
Signal transduction in vertebrate olfactory receptor neurons (ORNs) begins in the olfactory cilia when odor molecules bind to specific receptors and initiate a cascade of events leading to rapid cAMP formation, followed by the opening of $\mathrm{Ca}^{2+}$-permeable cyclic nucleotide-gated (CNG) cation channels (for review, see Lancet, 1986; Reed, 1992; Breer, 1993; Zufall et al., 1994). There is also evidence for an inositol 1,4,5-trisphosphate $\left(\mathrm{IP}_{3}\right)$ pathway causing elevation of intracellular $\mathrm{Ca}^{2+}\left(\left[\mathrm{Ca}^{2+}\right]_{\mathrm{i}}\right)$ (cf. Restrepo et al., 1996), but its precise role in odor transduction remains unclear (see Brunet et al., 1996).

$\left[\mathrm{Ca}^{2+}\right]_{i}$ plays important roles in regulating the sensitivity of olfactory transduction as part of the process underlying odor adaptation. An early phase of odor adaptation is triggered by cAMP-dependent $\mathrm{Ca}^{2+}$ entry. Removal of extracellular $\mathrm{Ca}^{2+}$ results in a less transient cAMP-induced whole-cell current and eliminates the phasic-tonic behavior of odor currents during maintained stimulation (Kurahashi, 1990; Kurahashi and Shibuya, 1990; Zufall et al., 1991b; Kurahashi and Menini, 1997). $\mathrm{Ca}^{2+}$. dependent feedback regulation also can be initiated by the $\mathrm{CO} /$ cGMP signaling system (Verma et al., 1993; Ingi and Ronnett,

Received Jan. 13, 1997; revised March 11, 1997; accepted March 18, 1997.

This work was supported in part by grants from National Institute on Deafness and Other Communication Disorders (NIDCD) to F.Z. (RO1 DC 02227), G.M.S. (RO1 DC 00086), and C.A.G. (RO1 DC 00210 and P50 NS 10174) and by NIDCD, NASA, and National Institute of Mental Health under the Human Brain Project (RO1MH52550) to G.M.S. We thank Diego Restrepo and Stan Kater for comments on this manuscript.

Correspondence should be addressed to Dr. Frank Zufall, Section of Neurobiology, Yale University School of Medicine, 333 Cedar Street, New Haven, CT 06510.

Dr. Rand's present address: Department of Neurology, University of Washington School of Medicine, 1959 NE Pacific Street, Box 356465, Seattle, WA 98195-6465.

Copyright (C) 1997 Society for Neuroscience $0270-6474 / 97 / 174136-13 \$ 05.00 / 0$
1995; Leinders-Zufall et al., 1995a), which leads, via persistent activation of $\mathrm{CNG}$ channels by cGMP, to the induction of a long-lasting form of odor adaptation (Leinders-Zufall et al., 1996; Zufall and Leinders-Zufall, 1997). Collectively, these results reveal complex effects of $\left[\mathrm{Ca}^{2+}\right]_{\mathrm{i}}$ in ORNs. A complete understanding of the role of $\left[\mathrm{Ca}^{2+}\right]_{i}$ requires, therefore, detailed knowledge about the temporal and spatial properties of $\mathrm{Ca}^{2+}$ changes caused by stimuli.

Several laboratories have applied $\mathrm{Ca}^{2+}$ imaging to address this problem and to monitor stimulus-induced events in ORNs. These studies detected elevations in $\left[\mathrm{Ca}^{2+}\right]_{\mathrm{i}}$ resulting from stimulation with single odor ligands or odor mixtures (Restrepo et al., 1990, 1993a,b; Restrepo and Boyle, 1991; Sato et al., 1991, 1994; Nakamura et al., 1994; Tareilus et al., 1995), forskolin (Sato et al., 1991; Restrepo et al., 1993b), or dialysis of ORNs with cAMP (Nakamura et al., 1994) or $\mathrm{IP}_{3}$ (Nakamura et al., 1994; Schild et al., 1995). Despite these abundant data, studies to date have not addressed $\mathrm{Ca}^{2+}$ signals in the cilia, the site of odor transduction. Thus, interpretation of the $\mathrm{Ca}^{2+}$ gradients seen in the dendrite and soma happened in the absence of any information about the events occurring at the transduction site. Additional mechanisms may regulate $\left[\mathrm{Ca}^{2+}\right]_{\mathrm{i}}$ in cellular compartments other than the cilia; microdomains of $\mathrm{Ca}^{2+}$ gradients may exist and function with relative independence. Therefore, the goal of the current study was to fill this gap in our knowledge by obtaining $\mathrm{Ca}^{2+}$ images of olfactory cilia. Using micropulse stimulation and high-resolution confocal microscopy, we detect $\mathrm{Ca}^{2+}$ transients in individual cilia resulting from $\mathrm{Ca}^{2+}$ entry through activated $\mathrm{CNG}$ channels, thus showing, for the first time, a spatial sequence of $\mathrm{Ca}^{2+}$ signaling in ORNs. 


\section{MATERIALS AND METHODS}

Preparation and solutions. Olfactory receptor neurons (ORNs) were freshly dissociated from the nasal epithelium of adult land-phase tiger salamanders (Ambystoma tigrinum), as previously described (Firestein et al., 1991b; Zufall et al., 1991b; Leinders-Zufall et al., 1995a), without the use of enzymes during the dissociation procedure. The epithelial sheets were cut carefully into small pieces $\left(<1 \mathrm{~mm}^{3}\right)$ and gently passaged in normal external solution (see below) several times through the firepolished tip of a Pasteur pipette. Suspended cells were collected with a pipette, and aliquots of $\sim 200 \mu \mathrm{l}$ were placed in a recording chamber on glass coverslips that had been coated previously with $0.1 \%$ laminin and $0.01 \%$ poly-L-lysine. This method was sufficient to ensure that the cells and their normally motile cilia became firmly attached to the coverslips (see Anderson and Hamilton, 1987). All cells used in this study were clearly identifiable as ORNs by their characteristic morphology, having a single thick dendrite with a knob-like swelling from which emanated 6-15 cilia.

Cells were held in a laminar flow chamber and superfused continuously at a rate of $\sim 100 \mu \mathrm{l} / \mathrm{sec}$ with physiological Ringer's solution containing (in $\mathrm{mM}$ ): $\mathrm{NaCl} 115, \mathrm{KCl} 2.5, \mathrm{CaCl}_{2} 1.0, \mathrm{MgCl}_{2}$ 1.5, HEPES 4.5, and Na-HEPES 4.5, pH 7.6, adjusted to 240 mOsm. To avoid a contribution to the measured $\mathrm{Ca}^{2+}$ signals from regenerative action potential discharges, we added $4 \mu \mathrm{M}$ tetrodotoxin (TTX) to this solution in all experiments, a dose that fully blocks currents through $\mathrm{Na}^{+}$channels in adult salamander ORNs (our unpublished observations). To reduce the external $\mathrm{Ca}^{2+}$ concentrations (as used for some experiments in Fig. 5), we buffered the bath solution with EGTA to give a free $\mathrm{Ca}^{2+}$ concentration of $\leq 1 \mu \mathrm{M}$. An estimate for this value was calculated from the stability constants, giving $0.6 \mu \mathrm{M}$ free $\mathrm{Ca}^{2+}$ (Leinders-Zufall et al., 1996). Chemicals were applied either in the bath or by micropipette pressure ejection, as described previously (Leinders-Zufall et al., 1996). In the latter case, different solutions were ejected from multibarrel glass pipettes that were placed within 5-10 $\mu \mathrm{m}$ from the cilia or, as in one type of experiment, from the cell soma. Stimulus pipettes were located downstream from the cells to avoid prestimulation. Under these conditions the solution switching time was $30-40 \mathrm{msec}$, as measured by the electrical response to elevated $\mathrm{K}^{+}$solutions (Leinders-Zufall et al., 1996).

ORN membrane potentials were analyzed by patch-clamping the neurons and using the current-clamp mode of an EPC-9 patch-clamp amplifier, as previously described (Leinders-Zufall et al., 1995a). The perforated patch-clamp technique with amphotericin B was used for these measurements (Leinders-Zufall et al., 1995a, 1996).

IBMX (3-isobutyl-1-methylxanthine) and LY83583 [6-(phenylamino)5,8-quinolinedione; Research Biochemicals International, Natick, MA] were prepared in DMSO. Dilutions were made fresh with final DMSO concentrations of $<0.1 \%(\mathrm{v} / \mathrm{v})$ and were delivered directly to individual cells via the multibarrel pipette. This concentration of DMSO has been shown not to alter the electrophysiological characteristics of salamander ORNs (Leinders-Zufall et al., 1995a). 8-Br-cGMP was dissolved in Ringer's solution. Unless otherwise stated, all chemicals were obtained from Sigma (St. Louis, MO).

Dye loading and calcium-imaging techniques. Intracellular $\mathrm{Ca}^{2+}$ was monitored with Fluo-3 AM (Molecular Probes, Eugene, OR), a membrane-permeant long wavelength fluorescence indicator, using techniques previously described (Leinders-Zufall et al., 1994). Fluo-3 AM was dissolved in a solution of DMSO and 20\% Pluronic F-127 (Molecular Probes), which then was added to normal Ringer's solution, sonicated briefly, and added to the experimental chamber to give a final concentration of $18 \mu \mathrm{M}$ Fluo-3 AM, 0.08\% Pluronic F-127, and 0.4\% DMSO. Cells were incubated in the dye solution for $60 \mathrm{~min}$ at room temperature and then perfused with dye-free Ringer's solution for $10 \mathrm{~min}$ before beginning the experiments. A laser scanning confocal system (Bio-Rad MRC-600, Hercules, CA) attached to an Olympus IMT-2 inverted microscope was used to visualize $\mathrm{Ca}^{2+}$-mediated fluorescence in the ORNs. The confocal system was equipped with a krypton-argon ion laser. A $60 \times, 1.4$ numeric aperture objective (Nikon) was used; images additionally were magnified 3-4× with the electronic zoom setting of the confocal microscope, which scanned a smaller area, using the same number of pixels in the image frame. The excitation illumination was $488 \mathrm{~nm}$; emitted fluorescence was collected with a long-pass filter for wavelengths $\geq 515 \mathrm{~nm}$. The confocal optical section was $\sim 1.5 \mu \mathrm{m}$ thick (estimated by the tilt-reflector method; Bio-Rad Technical Bulletin 101). Each ORN was imaged individually, with the optical section adjusted to show the cell body, dendrite, and cilia, if possible. High-resolution scans $(768 \times 512$ pixels/frame) were made either in standard confocal mode or, for phase contrast images, using a Bio-Rad transmitted light detector. Time series images were made by collecting $64 \times 64$ pixel fluorescence images at a rate of either 1 or $3 \mathrm{sec}^{-1}$. All scanning head settings except gain (i.e., black level, detector aperture, and laser neutral density filter) were kept the same over the series of experiments; the gain usually was adjusted slightly, but only once, at the beginning of the experiment during acquisition of the baseline image. High-resolution images of baseline fluorescence were taken for subsequent comparison with the time series images, and several images were acquired at the beginning of each time series before experimental solutions were applied. Eight-bit confocal image files were transferred to a Macintosh Quadra 800 microcomputer and analyzed with National Institutes of Health Image 1.59 software. Regions of interest corresponding to different cell compartments were outlined, and the average pixel values in these regions were measured. Data are presented in arbitrary fluorescence units or as relative changes in fluorescence intensity $(\Delta F)$ normalized to baseline fluorescence $(F)$.

Calibration procedures. We estimated $\left[\mathrm{Ca}^{2+}\right]_{\mathrm{i}}$ in ORNs in some experiments by using the calibration procedures of Kao et al. (1989) (also see Thomas and Delaville, 1991). Accordingly, the following equation was used to determine $\left[\mathrm{Ca}^{2+}\right]_{\mathrm{i}}$ at rest:

$$
\left[\mathrm{Ca}^{2+}\right]_{\mathrm{i}}=K_{\mathrm{d}}\left(F-F_{\min }\right) /\left(F_{\max }-F\right),
$$

in which $F$ is the measured baseline fluorescence intensity and $K_{\mathrm{d}}$ is the $\mathrm{Ca}^{2+}$-Fluo-3 dissociation constant $(400 \mathrm{nM}) . F_{\min }$ is the fluorescence intensity in the absence of $\mathrm{Ca}^{2+}$, and $F_{\max }$ is the fluorescence intensity of the $\mathrm{Ca}^{2+}$-saturated dye. Both parameters are calculated as average pixel values determined independently for each region of interest. $F_{\max }$ is calculated as $\left(F_{\mathrm{Mn}}-F_{\mathrm{bkg}}\right) / 0.2+F_{\mathrm{bkg}}$, in which $F_{\mathrm{Mn}}$ is the fluorescence intensity with ionomycin $(10 \mu \mathrm{M})$ and $\mathrm{MnCl}_{2}(2 \mathrm{mM})$, and $F_{\mathrm{bkg}}$ is the fluorescence intensity with ionomycin $(10 \mu \mathrm{M})$ and $\mathrm{MnCl}_{2}(2 \mathrm{mM})$ after lysis with $12 \mu \mathrm{M}$ digitonin. As detailed in Kao et al. (1989), we checked this procedure by measuring the fluorescence intensity during ionomycin treatment in $1 \mathrm{~mm}$ external $\mathrm{Ca}^{2+}$ before addition of $\mathrm{MnCl}_{2}$ and found that this value approached the calculated $F_{\max }$. We also tested for a potential contribution of extracellular indicator dye that might have been present even after washing by adding $0.1 \mathrm{mM} \mathrm{MnCl}_{2}$, which was chelated after $20 \mathrm{sec}$ with $0.25 \mathrm{~mm}$ diethylenetriaminepentaacetic acid (DTPA). There was no change in fluorescence, and thus a correction for extracellular dye was not necessary.

Data analysis. Data analyses and calculations were performed with Igor Pro software (WaveMetrics, Lake Oswego, OR) running on a Macintosh computer. Via this program user-defined functions in combination with an iterative Levenberg-Marquardt nonlinear, least-squares fitting routine were applied to the data. Unless otherwise stated, data are expressed as mean \pm SD and number of cells $(n)$. Statistical tests were performed with SuperAnova 1.1 (Abacus Software, Berkeley, CA). Fisher's LSD (least significant difference) test was used as a post hoc comparison of the ANOVA. Composite images were prepared with Adobe Photoshop 3.0 and printed on a Codonics NP 1600 color printer.

\section{RESULTS}

\section{Visualization of olfactory cilia}

To visualize changes in $\left[\mathrm{Ca}^{2+}\right]_{\mathrm{i}}$ in single olfactory cilia, we loaded ORNs with Fluo-3 AM $(18 \mu \mathrm{M})$ and observed them with a confocal microscope. We chose Fluo-3 as the $\mathrm{Ca}^{2+}$ indicator for this study because, among presently available indicators, it provides large optical signals per molecule and thus allows for the detection of $\mathrm{Ca}^{2+}$ transients in small cytoplasmic volumes (Minta et al., 1989). The data reported here were obtained from 115 individual ORNs, all of which had retained their cilia and showed the typical ORN morphology. Imaging of these neurons, in particular of the ciliary compartment, relies on the ability to immobilize the cells and the cilia on the substrate (see Materials and Methods). Figure 1 shows representative examples of ORNs as phase contrast and silhouette images to illustrate, after attachment and dye loading, the basic morphology and the four main compartments of the cells, including the soma, a single thick dendrite containing a knob-like swelling (termed olfactory knob) from which emanated half a dozen or more cilia (Fig. $1 A-E$ ). ORNs tended to retract their dendrites so that the overall dendritic length was reduced. 

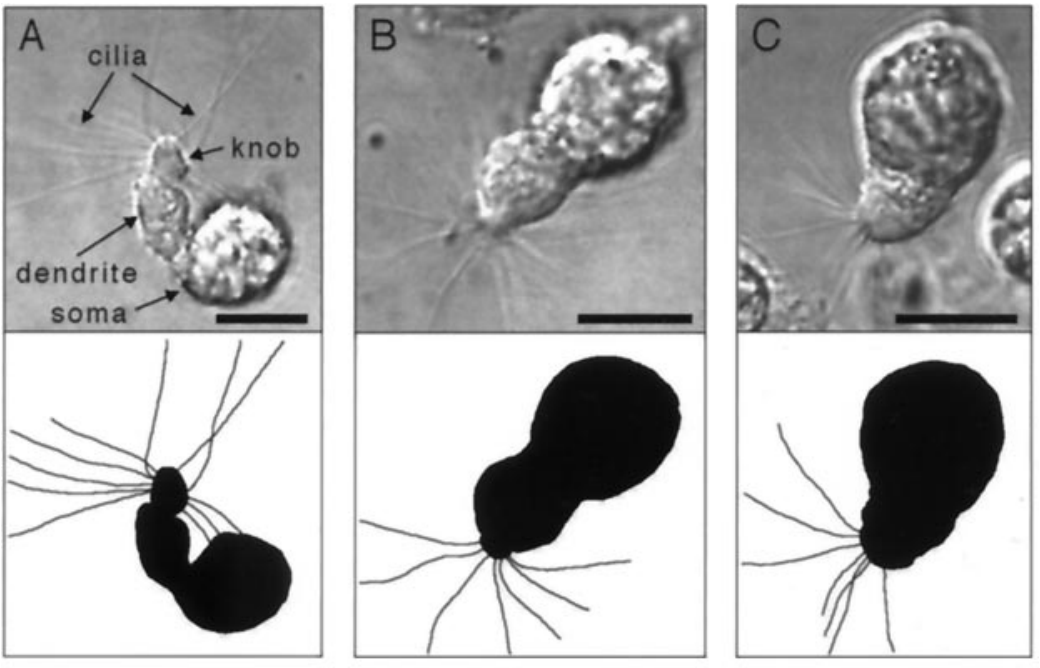

Figure 1. $A-E$, Morphology of acutely dissociated salamander olfactory receptor neurons after attachment and dye loading. Characteristic ORNs are shown as phase contrast and silhouette images. All studied neurons had intact cilia and a clearly identifiable dendritic knob. $F$, Example of the fluorescence intensity at rest (gray scale image) showing characteristic domains of higher fluorescence in discrete spots at the rim of the nucleus and at proximal and distal regions of the dendrite. The cilia are not detectable. Scale bars, $10 \mu \mathrm{m}$.

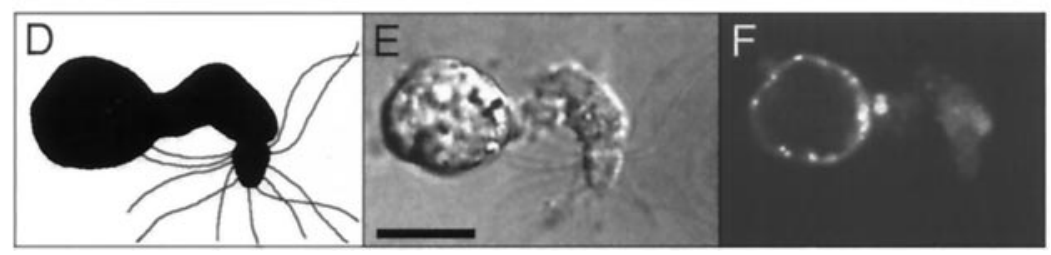

The morphology of the cilia, which are 200-300 $\mathrm{nm}$ in diameter (Simmons et al., 1981), was similar to that seen in earlier studies (Firestein et al., 1991b). Only those cells in which the majority of the cilia did not change their position during an experiment were included in the analysis. Individual cilia that moved during the course of an experiment were excluded from the analysis. Cells with longer dendrites were chosen for those experiments in which we were interested mainly in the spatiotemporal relation of $\mathrm{Ca}^{2+}$ fluorescence between dendrite and soma. However, there were no significant differences among the various morphological cell types with respect to their $\mathrm{Ca}^{2+}$ signaling.

A fluorescence image of a representative ORN at resting conditions is shown in Figure $1 F$. Fluorescence intensity at rest was generally rather low. In many ORNs, however, domains of higher fluorescence were detectable in discrete spots at the rim of the large nucleus and at proximal and distal portions of the dendrite (see also Fig. 2B, for comparison). These fluorescence spots corresponded to locations where cellular organelles such as variegated and multivesicular bodies, mitochondria, and endoplasmic reticulum have been described in ORNs (Simmons et al., 1981). It is unclear whether higher fluorescence in these locations represents dye accumulation in organelles or whether it is attributable to higher $\mathrm{Ca}^{2+}$ levels. Consistent with the very low resting fluorescence of Fluo-3, significant fluorescence signals associated with single cilia usually could not be detected in ORNs without stimulation of the cyclic nucleotide pathways (Fig. $1 F$; see also Fig. 5). In $\sim 15 \%$ of the cells, however, single cilia could be resolved faintly at rest. An example is seen in Figure $2 B$. Using the procedures described above (see Materials and Methods), we estimated the intracellular free $\mathrm{Ca}^{2+}$ concentration at rest to be $40.1 \pm 9.1 \mathrm{nM}(n=4)$ in the cilia and 57.5 $\pm 33.3 \mathrm{nM}(n=4)$ in the dendritic knob.

\section{$\mathrm{Ca}^{2+}$ transients induced by IBMX: spatiotemporal pattern}

To investigate the $\mathrm{Ca}^{2+}$ signals associated with activation of odor-sensitive CNG channels, we first stimulated the ORNs with the phosphodiesterase inhibitor IBMX. Previous experiments have shown that this treatment results in activation of the same transduction channels as odor stimulation (Firestein et al., 1991b; Lowe and Gold, 1993a), presumably via elevation of cAMP levels because of the high basal activity of olfactory adenylyl cyclase (see Lowe and Gold, 1993a). Because the CNG channels are highly permeable to $\mathrm{Ca}^{2+}$ (Zufall and Firestein, 1993; Frings et al., 1995), IBMX stimulation should increase $\left[\mathrm{Ca}^{2+}\right]_{i}$ in the ORNs. Averaged fluorescence images (pseudocolor scale) are depicted in Figure $2 B-D$ under three different conditions: (1) at rest before stimulation (Fig. 2B), (2) at peak fluorescence during a $1 \mathrm{~min}$ administration of IBMX (500 $\mu \mathrm{M})$ (Fig. 2C), and (3) after washout of IBMX and recovery of the fluorescence intensity to nearbaseline levels (Fig. 2D). The presence of IBMX caused a prominent, reversible increase in fluorescence across the entire cell. Particularly evident is the fluorescence signal associated with the characteristic "checkerboard" chromatin pattern of salamander ORN nuclei (Simmons et al., 1981), which can be observed in the soma region showing enhanced intensity during IBMX stimulation. A time series of images of the same experiment is shown in Figure $2 E$. Images were acquired before (first image, $0 \mathrm{sec}$ ), during (second to fifth image, 5-32 sec), and after recovery from stimulation with IBMX (last image, $93 \mathrm{sec}$ ). Note that the earliest IBMX-stimulated fluorescence increases took place in the cilia and the knob (see arrow in Fig. $2 E, 5 \mathrm{sec}$ ), followed by changes in the dendrite and soma (see images, 5-32 sec, Fig. 2E). Similar results were obtained in 15 other cells.

After stimulation of the cells, fluorescence increases in individual cilia could be resolved clearly. Figure $3 A$ illustrates a highresolution image taken at peak fluorescence showing the distal dendrite, knob, and several cilia of the same ORN as depicted in Figure 2. A quantitative comparison of the time course of the fluorescence signals was obtained from the outlined regions of three different cilia (Fig. 3B, areas 1-3) and a control region outside the cell (area 4 ). The analysis (Fig. 3C) revealed that the presence of IBMX $(500 \mu \mathrm{M})$ resulted in a significant increase in 
A

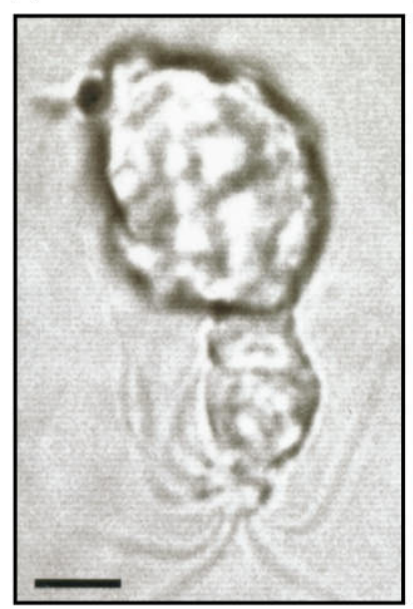

E

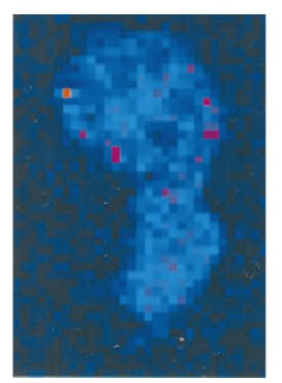

B

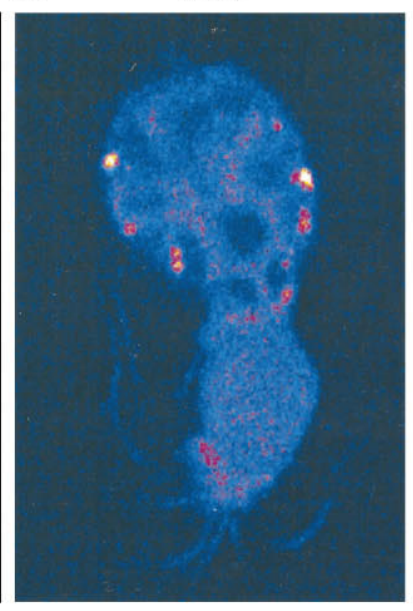

$5 s$

rest

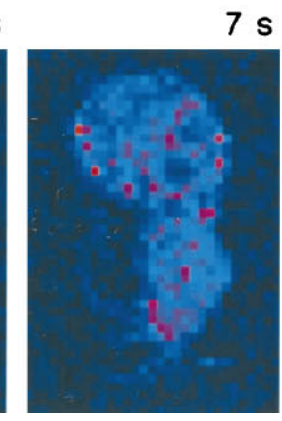

C

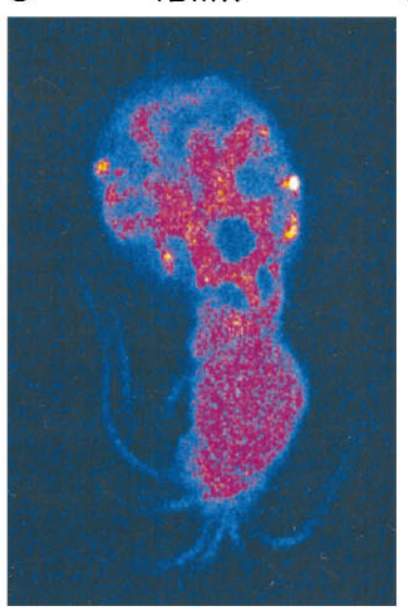

$9 \mathrm{~s}$
D recovery

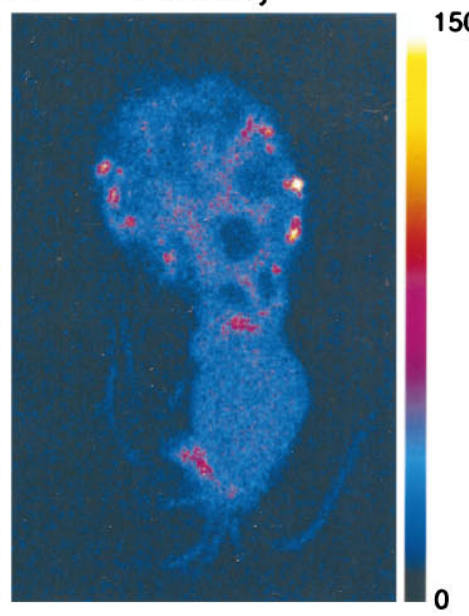

$32 \mathrm{~s}$
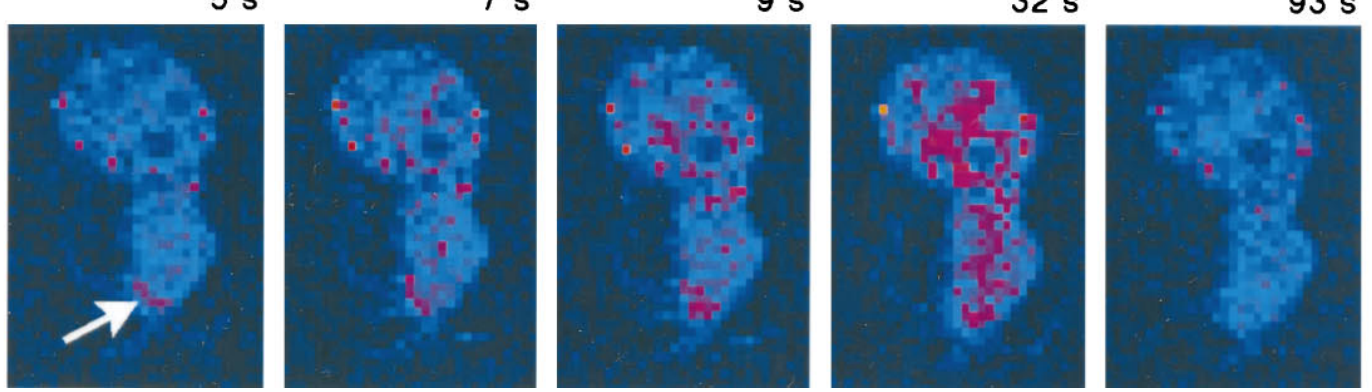

Figure 2. Effect of a 1 min administration of IBMX $(500 \mu \mathrm{M})$ on the $\mathrm{Ca}^{2+}$ fluorescence of an ORN. $A$, phase contrast image. Scale bar, $5 \mu \mathrm{m}$. $B-D$, Fluorescence images in pseudocolor scale taken at rest in the absence of $\operatorname{IBMX}(B)$, at peak fluorescence in the presence of IBMX $(C)$, and after wash-out of IBMX and recovery of fluorescence intensity to near baseline levels ( $49 \mathrm{sec}$ after the end of the IBMX stimulus; $D$ ). Images were generated by averaging four individual frames together, using the Kalman filter function of the confocal system. $E$, Time series images of the same ORN acquired during the first $32 \mathrm{sec}$ of stimulation with IBMX and after recovery of the fluorescence signal $(93 \mathrm{sec})$. Sampling rate, $3 \mathrm{~Hz}$. Images are labeled in seconds, starting from an arbitrary zero time point; the stimulus was triggered at $2.5 \mathrm{sec}$. The earliest increases in $\mathrm{Ca}^{2+}$ fluorescence took place in the cilia and the olfactory knob (arrow, $5 \mathrm{sec}$ ), followed by changes in the dendrite and cell body (frames $7 \mathrm{sec}-32 \mathrm{sec}$ ).

$\mathrm{Ca}^{2+}$ fluorescence within these three regions but did not induce a measurable increase in the control region. Despite the continuous presence of IBMX the time course of the fluorescence increase was transient. The IBMX stimulus produced very similar time courses of $\mathrm{Ca}^{2+}$ fluorescence in the three different cilia. The signal reached its peak within $3.85-4.88 \mathrm{sec}$. The decay phase of the traces was fit with single exponential functions, giving time constants $\left(\tau_{\text {off }}\right)$ ranging from 5.68 to $11.81 \mathrm{sec}$. The relative increase in fluorescence in the three cilia was similar, ranging from 41 to $58 \%$. This suggests that the calculated fluorescence changes represented the expected cellular response caused by stimulation with IBMX. Because the ciliary membrane does not contain voltage-activated ion channels (see below), IBMX-induced increases in fluorescence in this compartment theoretically should be attributable entirely to CNG channel activation, even under the nonvoltage-clamp conditions used here. Evidence for this view is given by the close match of the time courses of the signals of Figure $3 C$ with the ionic currents through $\mathrm{CNG}$ channels during continuous intracellular perfusion by cyclic nucleotides (Kurahashi, 1990; Firestein et al., 1991a; Leinders-Zufall et al., 1995a). Together with the fact that olfactory CNG channels are strongly permeable to $\mathrm{Ca}^{2+}$, these results thus suggest that the increase in fluorescence in the cilia resulted from $\mathrm{Ca}^{2+}$ influx through activated $\mathrm{CNG}$ channels.

To compare the spatiotemporal pattern of IBMX-induced fluo- rescence changes in the various cellular compartments in more detail, we next stimulated ORNs with brief pulses (1 sec) of IBMX $(500 \mu \mathrm{M})$ (Lowe and Gold, 1993a). Stimuli were applied locally such that only the cilia came in contact with the test solution, but not the rest of the ORN, as done in previous electrophysiological experiments (Lowe and Gold, 1991). This technique has not yet been applied to the analysis of $\mathrm{Ca}^{2+}$ signals in ORNs. This treatment was sufficient to elicit marked fluorescence increases in all four major compartments of a given ORN $(n=19)$. A characteristic example is depicted in Figure $4 A$, and results from several experiments are summarized in Table 1 . The IBMX stimulus evoked a brief $\mathrm{Ca}^{2+}$ transient in a given cilium with a time to peak of 3 sec. The decay time course could be well fit by a monoexponential function yielding a time constant $\tau_{\text {off }}=2.8 \mathrm{sec}$ (Fig. 4A,B). The time course of the fluorescence signal measured in the knob was qualitatively similar although slightly slower (see comparison in Table 1). In contrast, the fluorescence increases in the dendrite and the soma resulting from the IBMX pulse showed very different temporal behavior. Most notably, they were sustained for a longer period before recovering back to baseline, often for $>60 \mathrm{sec}$ (Fig. $4 A, B$ ). The $\mathrm{Ca}^{2+}$ fluorescence in the dendrite displayed the slowest recovery of the four different compartments $(n=6)$ (see Table 1$)$. Its recovery time course displayed complicated kinetics (Fig. 4A), suggesting that several distinct mechanisms contributed to the overall fluorescence in- 
Figure 3. Time course of IBMX-stimulated fluorescence increases (500 $\mu \mathrm{M}$ IBMX) analyzed in different cilia of the same ORN as that depicted in Figure 2. A, High-resolution confocal image (gray scale) taken at peak fluorescence intensity. Individual cilia are clearly identifiable. Scale bar, $2 \mu \mathrm{m}$. $B$, Same image as in $A$ but with outlined regions of interest indicating where average fluorescence intensity was measured. $C$, Plot of the time course of fluorescence increases stimulated by IBMX in the four different regions. The control area (4) that lacks cilia did not show any significant fluorescence change. Recovery of the signals was fit with single exponential functions, as indicated by the continuous lines, giving decay time constants of $7.4 \mathrm{sec}$ (region 1), $5.7 \mathrm{sec}$ (region 2), and 11.8 $\sec ($ region 3).
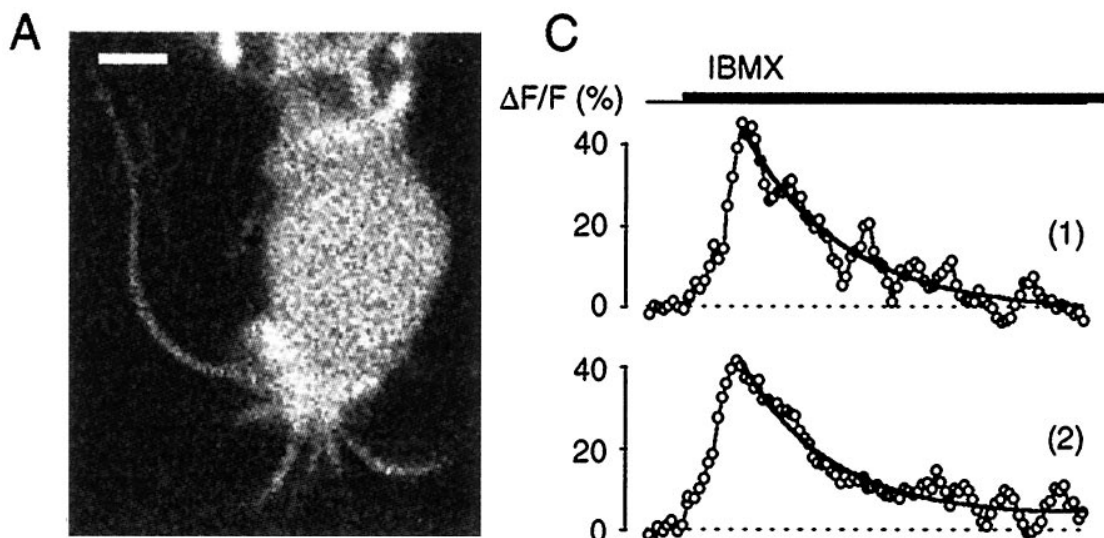

B

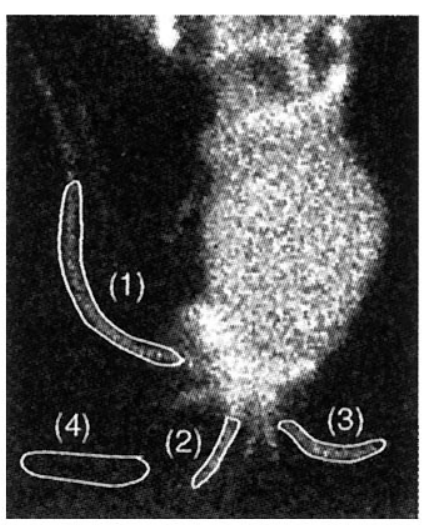

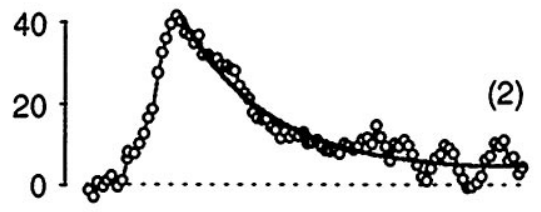
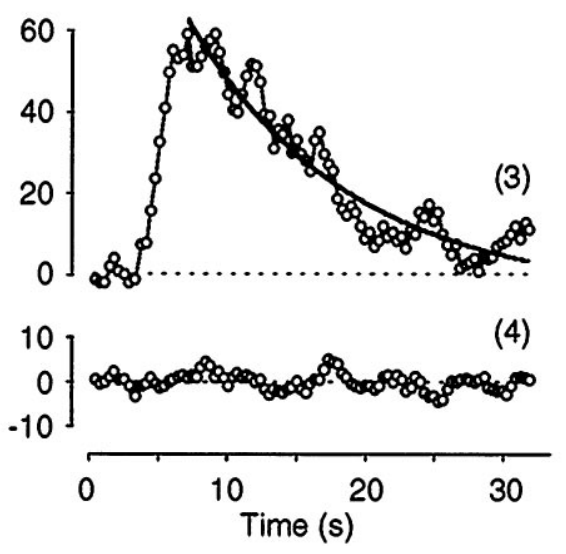

Table 1. Analysis in various cellular compartments of temporal properties of fluorescence increases resulting from a 1 sec pulse of IBMX

\begin{tabular}{|c|c|c|c|c|c|}
\hline & $n$ & $\begin{array}{l}\Delta F / F \\
(\%)\end{array}$ & $\begin{array}{l}\text { Time to peak } \\
(\mathrm{sec})\end{array}$ & $\begin{array}{l}\text { Recovery time } \\
(\mathrm{sec})\end{array}$ & $\begin{array}{l}\tau_{\text {off }} \\
(\mathrm{sec})\end{array}$ \\
\hline Cilium & 19 & $17.6 \pm 7.5$ & $2.5 \pm 1.1$ & $8.3 \pm 2.2$ & $2.7 \pm 0.9$ \\
\hline Knob & 6 & $28.1 \pm 10.1$ & $5.3 \pm 1.5$ & $18.8 \pm 5.6$ & $11.5 \pm 2.1$ \\
\hline Dendrite & 6 & $46.3 \pm 23.4$ & $6.3 \pm 1.6$ & $70.8 \pm 12.5$ & n.d. \\
\hline Soma & 6 & $59.8 \pm 21.7$ & $6.8 \pm 1.3$ & $59.5 \pm 11.9$ & n.d. \\
\hline
\end{tabular}

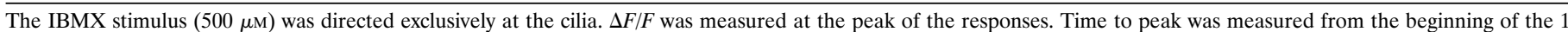

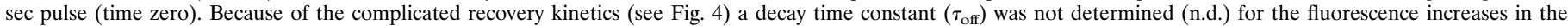
dendrite and soma.

crease in the dendrite. To compare the onset and offset rates of the $\mathrm{Ca}^{2+}$ fluorescence in the different compartments in more detail, we rescaled signals to give identical peak amplitudes and plotted them at two different time scales (Fig. 4B,C). There was a clear temporal relation among the fluorescence increases in the various compartments. IBMX-stimulated $\mathrm{Ca}^{2+}$ fluorescence was detected first in the cilia and, with a slight delay, also in the knob. There was, however, a marked delay between the ciliary signal and the fluorescence change in the dendrite and soma. Interestingly, the rise of the signals in dendrite and soma occurred at a time when the ciliary response already was decaying. These results are fully consistent with previous evidence indicating that the cilia are the primary site of olfactory signal transduction and that they contain the highest density of CNG channels (cf. Zufall et al., 1994). These data also suggest that the fluorescence increases monitored in the dendrite and the soma probably reflect the activity of additional $\mathrm{Ca}^{2+}$ signaling mechanisms secondary to the primary transduction events because of $\mathrm{CNG}$ channel activation.

\section{IBMX-stimulated fluorescence increase depends on $\mathrm{Ca}^{2+}$ entry through CNG channels}

To investigate further the precise source of the ciliary fluorescence increases, we performed two additional tests. To examine whether the fluorescence change depended on $\mathrm{Ca}^{2+}$ entry or whether it was caused by intracellular release of $\mathrm{Ca}^{2+}$, we measured the IBMX responses in the presence of lowered extracellular $\mathrm{Ca}^{2+}$ concentrations. Figure $5 A-E$ illustrates an example in which IBMX-stimulated $\mathrm{Ca}^{2+}$ fluorescence was measured under two different conditions of external $\mathrm{Ca}^{2+}$ concentration, with physiological levels of $1 \mathrm{mM} \mathrm{Ca}{ }^{2+}$ and with $\mathrm{Ca}^{2+}$ lowered to $\leq 1$ $\mu \mathrm{M}$ (Leinders-Zufall et al., 1996). The temporal analysis of the same experiment is depicted in Figure $5 F$. At resting conditions the baseline fluorescence in this ORN was very low so that the cilia were barely detectable (Fig. 5B). Stimulation with IBMX in the presence of $1 \mathrm{mM} \mathrm{Ca}^{2+}$ caused a marked increase in $\mathrm{Ca}^{2+}$ fluorescence of the cilia $(17.2 \%)$ with the characteristic transient time course (Fig. 5C,F). However, under conditions in which the 


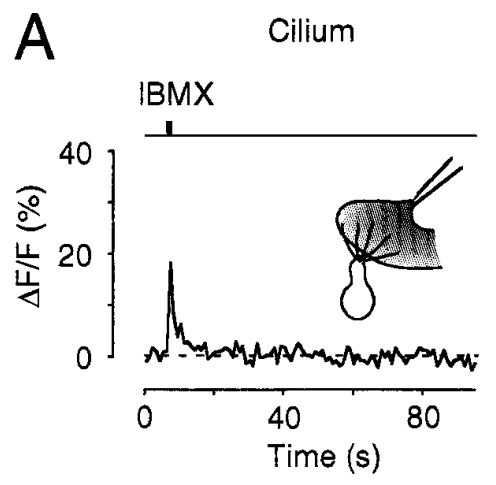

B

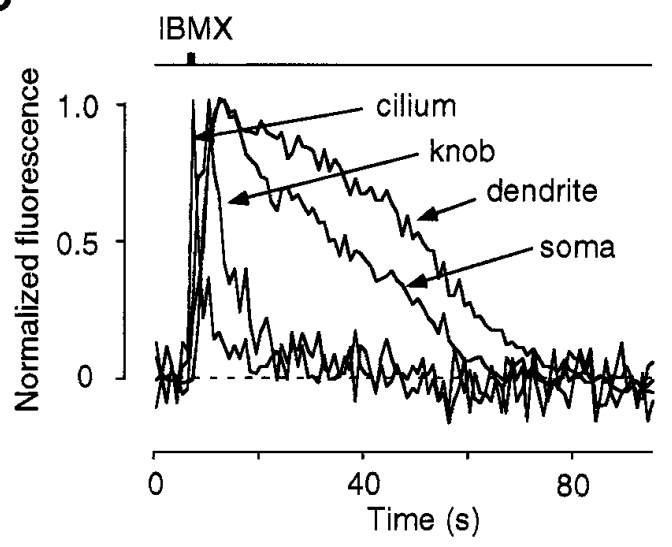

Knob

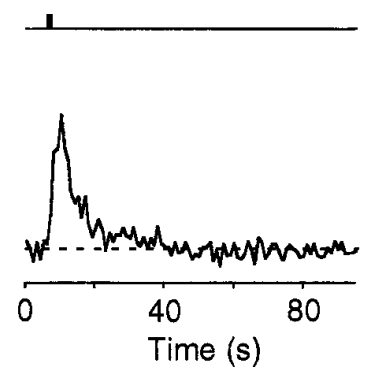

Time (s)
Dendrite
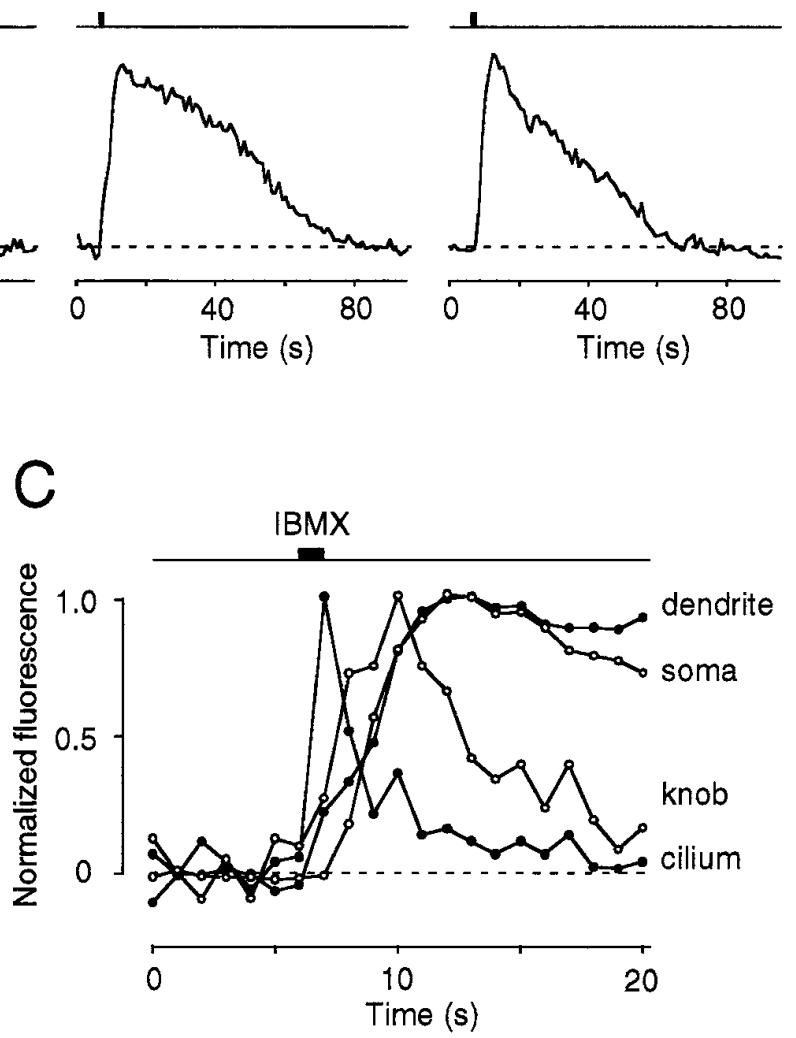

Figure 4. Spatiotemporal analysis of $\mathrm{Ca}^{2+}$ fluorescence stimulated by a brief pulse of IBMX (500 $\mu$ M applied for $1 \mathrm{sec}$ ). The stimulus was directed exclusively at the cilia. $A$, Comparison of the time courses of fluorescence increases evoked by a brief IBMX pulse. The signal in any given cilium shows the highest rate of activation and recovery. In contrast, fluorescence increases in the dendrite and soma remained sustained for tens of seconds after a brief stimulus (compare Table 1). Note that the magnitude of relative changes in fluorescence in a given cilium cannot be compared directly with those in the knob or other parts of the ORN, because the diameter of a single cilium was much smaller than the optical section of the confocal microscope. $B, C$, For a better comparison of the time courses, fluorescence signals from $A$ are rescaled to give the same peak amplitudes and are plotted at two different time scales. Sampling rate, $1 \mathrm{~Hz}$.

external $\mathrm{Ca}^{2+}$ was lowered, the same IBMX stimulus failed to induce any measurable fluorescence increase (Fig. 5D,F). Full recovery of the original IBMX response occurred after restoring the $\mathrm{Ca}^{2+}$ level in the bath solution (Fig. $\left.5 E, F\right)(n=5)$. This experiment indicates that $\mathrm{Ca}^{2+}$ entry was essential for the generation of IBMX-stimulated fluorescence signals in the cilia. We also found no detectable fluorescence change in other ORN compartments under lowered external $\mathrm{Ca}^{2+}$ (data not shown), which further underscores the notion that $\mathrm{Ca}^{2+}$ entry is the primary $\mathrm{Ca}^{2+}$ source for the generation of the measured signals.

Second, we tested whether the ciliary fluorescence changes depended on $\mathrm{Ca}^{2+}$ permeation through $\mathrm{CNG}$ channels by using a pharmacological blocker for CNG channels, LY83583 (LeindersZufall and Zufall, 1995). LY83583 can be applied from the external side, shows rapid and complete recovery from its blockade of CNG channels on wash-out, and appears to block ionic flux through $\mathrm{CNG}$ channels by binding to the open channel pore (Leinders-Zufall and Zufall, 1995). Consistent with these results, the IBMX-stimulated fluorescence increase was abolished nearly fully in the presence of LY83583 (40 $\mu \mathrm{M} ; n=3)$ (Fig. 5G). The effect of LY83583 was reversible on wash-out of the drug (Fig. $5 G)$. Collectively, these two experimental approaches provide strong evidence to conclude that the measured increases in fluorescence in the cilia were caused by $\mathrm{Ca}^{2+}$ entry through $\mathrm{CNG}$ channel activation.

\section{Fluorescence changes in response to 8-Br-cGMP}

Native olfactory CNG channels are known not only to be gated by cAMP but also by cGMP (Nakamura and Gold, 1987; Zufall et al., 1991a; Frings et al., 1992). Given that cGMP mediates the induction of a long-lasting form of odor adaptation (Leinders-Zufall et al., 1996; Zufall and Leinders-Zufall, 1997), interest has focused on the mechanisms by which cGMP elevation leads to olfactory adaptation. Because the build-up of cGMP in ORNs is slow, reaches only low micromolar levels, and can outlast the primary cAMP-mediated odor response for minutes (Breer et al., 1992; Verma et al., 1993; Leinders-Zufall et al., 1995a), endogenous odor-stimulated cGMP formation results in currents through CNG channels with small amplitudes but minute-long time courses (Leinders-Zufall et al., 1996; Zufall and Leinders-Zufall, 1997). We have hypothesized that ionic flux through these persistent currents causes significant $\mathrm{Ca}^{2+}$ accumulation in olfactory cilia as part of $\mathrm{Ca}^{2+}$-dependent feedback regulation. To test this idea, we exposed ORNs to low amounts of 8-Br-cGMP (1 $\mu \mathrm{M})$ 


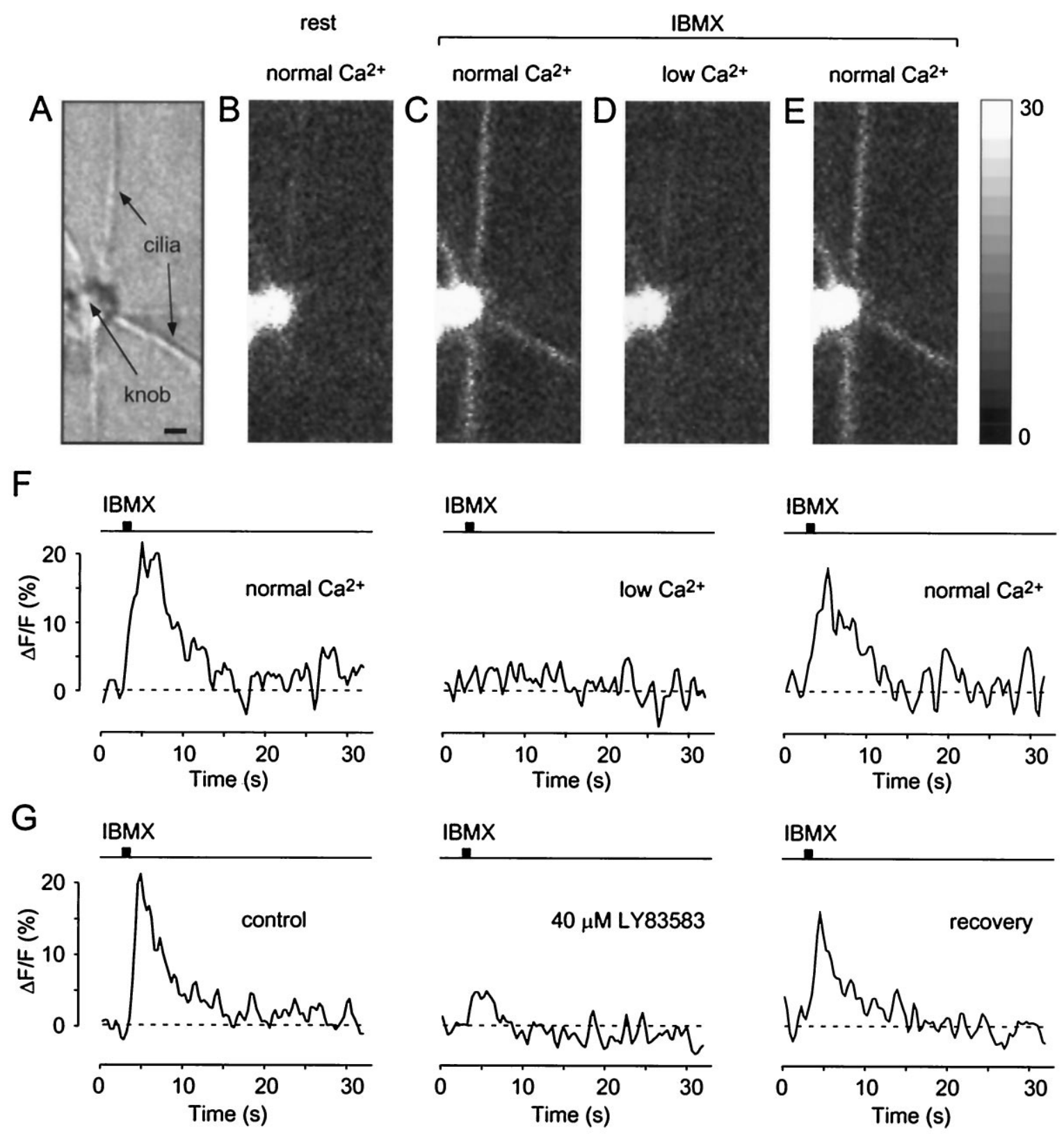

Figure 5. Evidence that IBMX-stimulated fluorescence increases in the cilia depend on $\mathrm{Ca}^{2+}$ entry through activated $\mathrm{CNG}$ channels. $A$, Phase contrast image of an ORN showing the dendritic knob and several cilia. Scale bar, $1 \mu \mathrm{m}$. B, High-resolution image (gray scale) of the same ORN indicating the fluorescence intensity at rest, with normal $(1 \mathrm{mM}) \mathrm{Ca}^{2+}$ in the extracellular bath solution. $C$, After an IBMX pulse the cilia show enhanced fluorescence intensity and are clearly resolvable. $D$, The same IBMX pulse fails to increase significantly the ciliary fluorescence levels in lowered external Ca ${ }^{2+}(\leq 1$ $\mu \mathrm{M}) . E$, The IBMX-induced fluorescence increase recovers after normal $\mathrm{Ca}^{2+}$ levels are restored in the bath solution. $F$, Analysis of the time courses of IBMX-induced fluorescence increases in one cilium under various conditions of external $\mathrm{Ca}^{2+}$ concentration, the same experiment as in $B-E$; sampling rate, $3 \mathrm{~Hz}$. $G$, Effect of the CNG channel blocker LY83583 (40 $\mu \mathrm{M})$ on IBMX-stimulated fluorescence changes. The IBMX-induced signal is abolished nearly fully in the presence of LY83583. The effect of LY83583 can be reversed after wash-out of the drug.

(Fig. 6A,B). This low cGMP concentration was sufficient to produce significant fluorescence increases in olfactory cilia. The cGMP-stimulated fluorescence increase developed on a slow time course, reaching a sustained plateau within $\sim 2$ min. More importantly, the increase in fluorescence was confined locally to the cilia and the knob $(n=5)$ (Fig. $6 A, B)$. With a delay of $\sim 40 \mathrm{sec}$ a much smaller increase in fluorescence could be detected in the dendritic compartment, whereas a fluorescence change in the soma was barely detectable. 8-Br-cGMP-stimulated fluorescence increases were blocked reversibly by LY83583 (20 $\mu \mathrm{M})$ (data not shown), consistent with CNG channel activation (Leinders-Zufall and Zufall, 1995). Stronger stimulation with 8-Br-cGMP (100 $\mu \mathrm{M})$ also promoted marked fluorescence increases in all parts of the ORN (Fig. 6B). These data indicate that steep $\mathrm{Ca}^{2+}$ gradients between single cilia and the dendrite and soma, lasting several minutes, developed on weak stimulation with cGMP. Thus, cGMP concentrations known to occur in ORNs after brief odor stimuli could serve to maintain elevated $\mathrm{Ca}^{2+}$ levels in olfactory cilia for time spans an order of magnitude longer than the cAMP-mediated responses. 


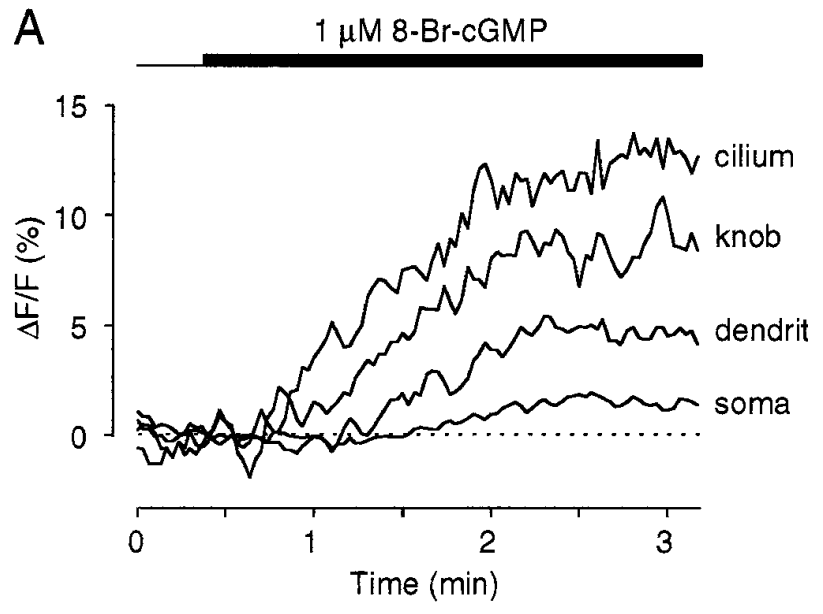

B

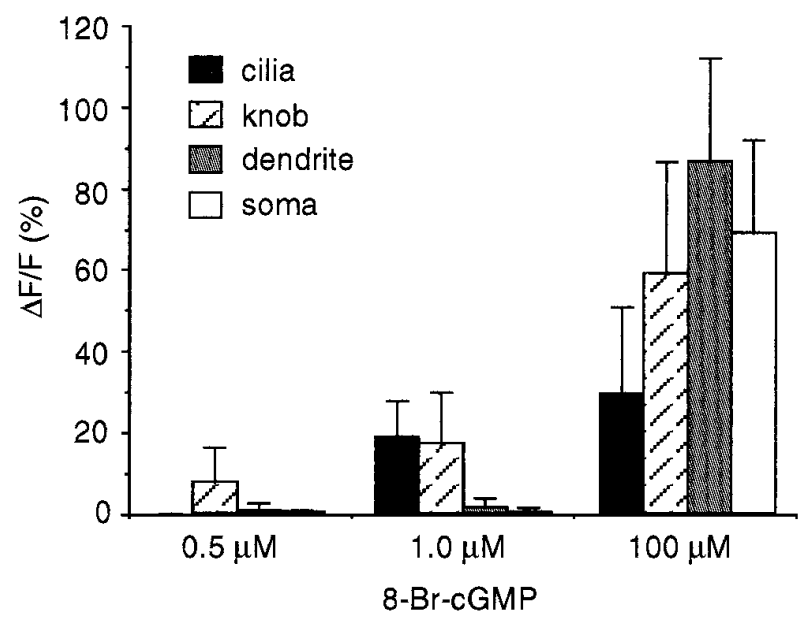

Figure 6. Differential effects of weak and strong stimulation with 8-BrcGMP on $\mathrm{Ca}^{2+}$ fluorescence in ORNs. $A$, Temporal analysis of the effect of $1 \mu \mathrm{M} 8$-Br-cGMP on fluorescence levels in various cellular compartments. The rising phase of the ciliary response can be fit with a single exponential function with a time constant of $\tau_{\text {on }}=67 \mathrm{sec}$. Note that there is a slow, cumulative increase in $\mathrm{Ca}^{2+}$ fluorescence in a given cilium, reaching a plateau after $\sim 2$ min. $B$, Plot showing the increase in $\mathrm{Ca}^{2+}$ fluorescence resulting from various concentrations of 8 -Br-cGMP $(0.5,1$, and $100 \mu \mathrm{M})$ analyzed in the four main compartments of the neurons. Low levels of 8-Br-cGMP $(0.5-1 \mu \mathrm{M})$ produced spatially heterogeneous fluorescence changes that were locally restricted to the cilia and the knob Large fluorescence increases could be detected in all neuronal compartments after strong stimulation with 8-Br-cGMP $(100 \mu \mathrm{M})$. The following increases in fluorescence were measured: $0.5 \mu \mathrm{M}$ 8-Br-cGMP, $7.5 \pm 8.7 \%$ (knob), $0.75 \pm 1.5 \%$ (dendrite), 0\% (soma); $1 \mu \mathrm{M}$ 8-Br-cGMP, $18.7 \pm$ $8.9 \%$ (cilium), $17.3 \pm 12.5 \%$ (knob), $1.3 \pm 2.5 \%$ (dendrite), $0.5 \pm 1.0 \%$ ( soma); $100 \mu \mathrm{M}$ 8-Br-cGMP, $29.3 \pm 21.5 \%$ (cilium), $58.7 \pm 27.8 \%$ (knob), $86.5 \pm 25.4 \%$ (dendrite), $68.8 \pm 22.8 \%$ (soma).

\section{Are there domains of higher fluorescence in various parts of individual cilia?}

Previous ultrastructural experiments have suggested that the distal cilia are the main site of olfactory signal transduction, containing the molecular components of the cyclic nucleotide cascade (Menco et al., 1992; Menco, 1994). We therefore examined whether the fluorescence increase resulting from CNG channel activation showed a heterogeneous distribution in individual cilia, displaying higher intensity at distal cilia as compared with more proximal regions (Fig. 7). Potential problems in this analysis could result from the fact that the diameter of a given cilium is not constant over its length (Menco, 1994) and that the optical section of the confocal microscope used here was larger than the ciliary diameter. Thus, differences in fluorescence intensity over the length of a given cilium simply could reflect differences in the path length and the number of dye molecules. To avoid this problem, we measured the relative decrease in cGMP-induced fluorescence (100 $\mu \mathrm{M} 8$ 8-Br-cGMP) that occurred on blocking the CNG channels by LY83583 $(20 \mu \mathrm{M})($ Fig. $7 A, B)$. For the analysis the cilia were divided into proximal, medial, and distal regions (Fig. $7 C$ ), and the relative changes in fluorescence intensity in these outlined areas were compared (Fig. 7D). The LY83583-mediated decline in fluorescence intensity was quite constant in different regions of a given cilium, showing no significant differences (Fig. 7D). There was also very little difference among individual cilia (Fig. 7D). Thus, at the level of resolution obtainable, there was no evidence in single cilia for a heterogeneous pattern of fluorescence changes with respect to $\mathrm{CNG}$ channel activation, consistent with conclusions from previous electrophysiological recordings (Lowe and Gold, 1991).

\section{Fluorescence changes in response to membrane depolarization by elevated $\mathbf{K}^{+}$}

The existence of marked fluorescence increases in olfactory cilia generated by activation of $\mathrm{CNG}$ channels raised the question of the extent to which these changes were mediated by depolarization of the ORN and, in particular, whether subsequent $\mathrm{Ca}^{2+}$ entry through voltage-gated $\mathrm{Ca}^{2+}$ channels could account for the detected signals. To discriminate between these possibilities, we used micropulse stimulation with elevated external $\mathrm{KCl}$ solutions and measured the differential fluorescence changes in different cellular compartments.

The first aim was to stimulate the neurons with a $120 \mathrm{~mm} \mathrm{KCl}$ pulse $(1 \mathrm{sec})$, which is sufficient to drive the ORN membrane potential to values positive of $0 \mathrm{mV}$. This treatment failed to elicit any detectable fluorescence increase if the stimulus was directed exclusively at the cilia (Fig. $8 A)(n=6)$. This result reinforces the notion that the spatial distribution of ion channels in the ORNs is highly asymmetric and that the cilia lack significant voltageactivated membrane channels (cf. Zufall et al., 1994). When the soma of the ORNs was stimulated with a $120 \mathrm{~mm} \mathrm{KCl}$ pulse, a marked and rapid increase in $\mathrm{Ca}^{2+}$ fluorescence was detected in the soma compartment $(32 \pm 21 \%)$ (Fig. $8 B)$. The fluorescence signal reached its peak within $2.7 \pm 0.8 \mathrm{sec}(n=7)$ and decayed on an exponential time course with a time constant of $16.6 \pm 11.1$ $\sec (n=7)$. This signal was most likely attributable to activation of high voltage-gated $\mathrm{Ca}^{2+}$ channels, followed by $\mathrm{Ca}^{2+}$ entry (Schild et al., 1994). Temporally similar but smaller fluorescence changes were detectable simultaneously in the dendrite and knob (Fig. $8 B$ ). Notably, there was no detectable fluorescence increase in the cilia $(n=7)$ (Fig. $8 B)$. These data rule out the possibility that the ciliary fluorescence changes caused by activation of $\mathrm{CNG}$ channels resulted from backpropagation of $\mathrm{Ca}^{2+}$ from the dendritic compartment and that activation of voltage-dependent $\mathrm{Ca}^{2+}$ channels contributed to the measured fluorescence changes in the olfactory cilia.

Previous work has suggested that high voltage-activated $\mathrm{Ca}^{2+}$ channels are the predominant form of $\mathrm{Ca}^{2+}$ channels in ORNs and that membrane potentials sufficient to gate these channels probably are reached only during action potential generation (Schild et al., 1994). To evaluate this hypothesis further, we measured the membrane potentials (receptor potentials) resulting 
A

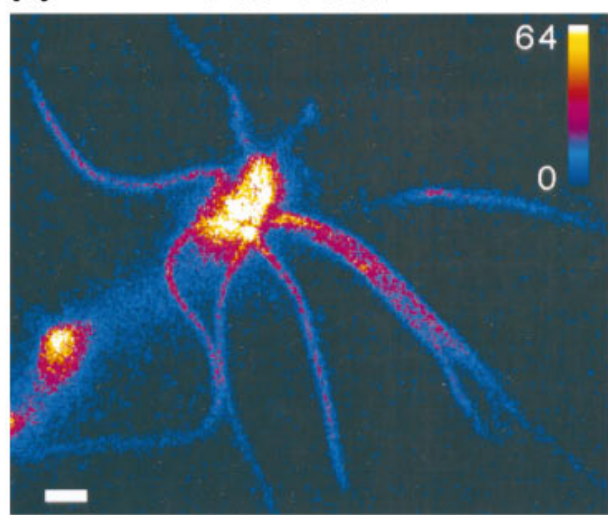

Figure 7. Lack of evidence for the existence of subdomains of higher fluorescence within individual cilia of an ORN. $A$, High-resolution image (4 averages) in pseudocolor scale taken in the presence of $1 \mathrm{~mm}$ 8-Br-cGMP showing strong fluorescence intensity in the distal dendrite, knob, and eight individual cilia. Scale bar, $1 \mu \mathrm{m}$. $B$, Same ORN in the presence of $1 \mathrm{mM} \quad 8$-Br-cGMP plus $20 \mu \mathrm{M}$ LY83583. As a result of CNG channel blockade by LY83583, the fluorescence intensity is decreased markedly but recovers back to high levels on wash-out of the blocker (data not shown). $C$, Drawing illustrating the ciliary regions in which fluorescence intensity was measured. Each cilium was subdivided into proximal (gray), medial (white), and distal (black) areas. $D$, Plot of the relative decrease in fluorescence levels mediated by LY83583 in various cilia (indicated by the numbers $1-8$ ) and in subciliary parts (proximal, medial, and distal, as indicated in $C$ ). There is no significant difference in fluorescence changes in the various regions (LSD, $p=0.42-0.71)$.
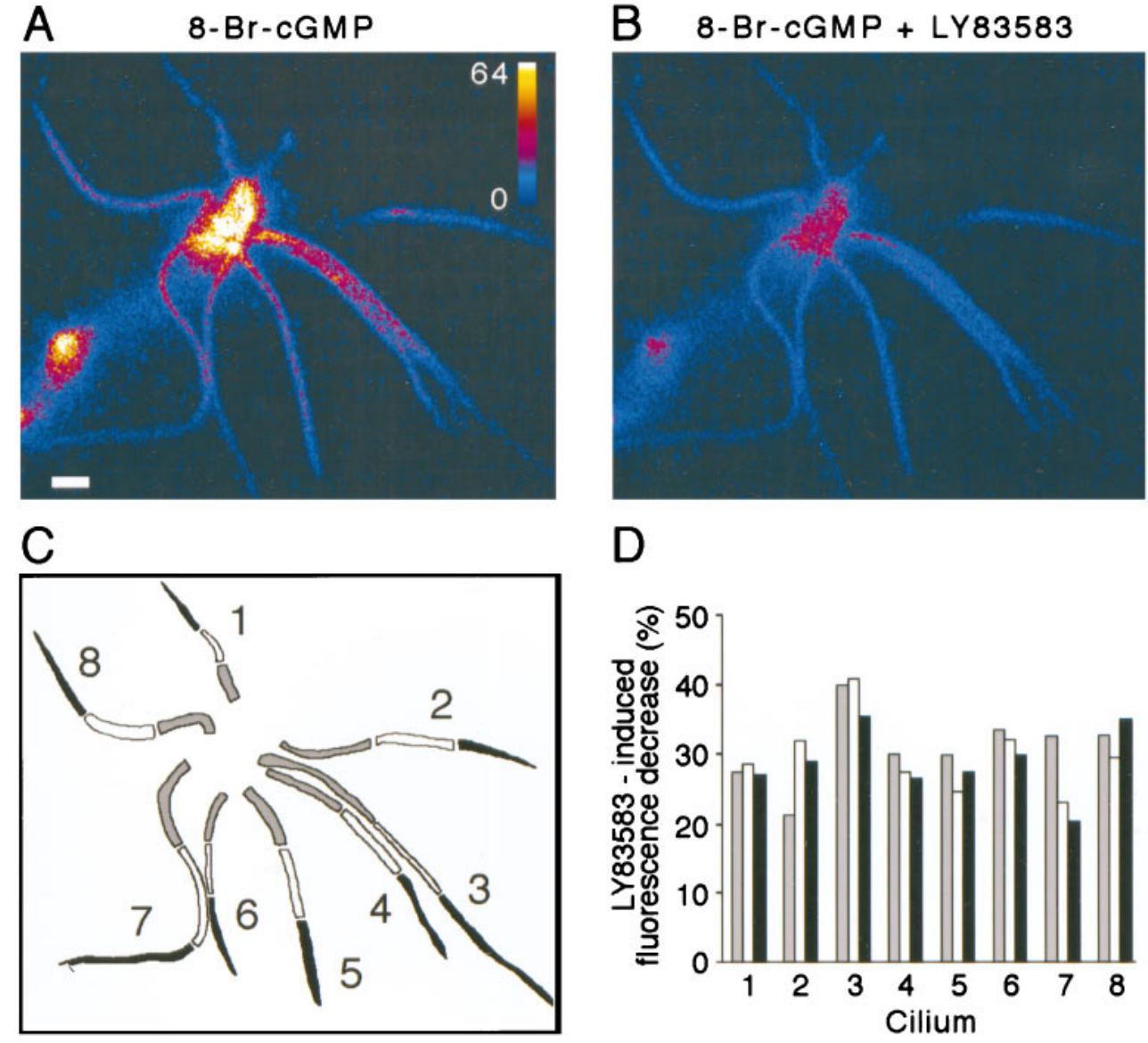

D

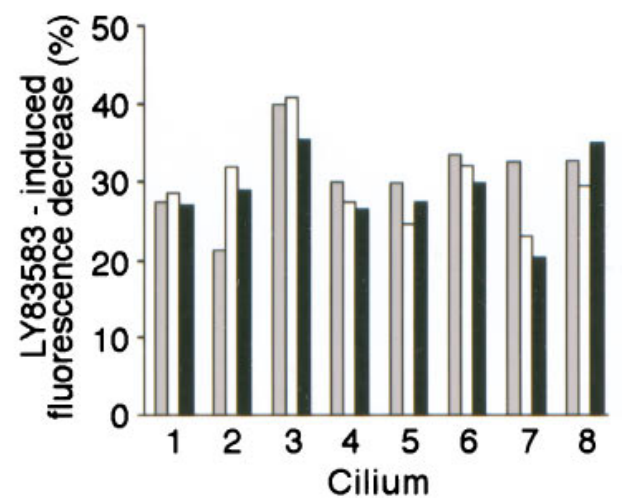

from stimulation of the ORNs with saturating concentrations of either IBMX $(500 \mu \mathrm{M}), 8-B r-c G M P(100 \mu \mathrm{M})$, or the odor ligand cineole $(100 \mu \mathrm{M})$ by using the current-clamp mode of the patchclamp amplifier. The perforated patch technique was applied in these experiments (Leinders-Zufall et al., 1995a, 1996), and the cells were held in TTX $(4 \mu \mathrm{M})$ to avoid impulse discharges. Under these experimental conditions the maximal membrane potential elicited by any of the three stimuli reached $-27.1 \pm 3.4 \mathrm{mV}(n=$ 9 ). This indicates that the voltage- and time-dependent conductances in the dendrite and soma of salamander ORNs are adjusted in a manner that ensures that the receptor potential never reaches levels positive to approximately $-25 \mathrm{mV}$. The same extent of depolarization can be generated by a $20 \mathrm{mM} \mathrm{KCl}$ pulse ( $1 \mathrm{sec}$ ) directed at the ORN soma (data not shown). The fluorescence changes resulting from a $20 \mathrm{~mm} \mathrm{KCl}$ stimulus are illustrated in Figure $8 C$. The results indicate that depolarization of the ORN membrane potential to $-25 \mathrm{mV}$ was not sufficient to generate fluorescence changes comparable to those of Figure $8 \mathrm{~B}$. Except for a small and delayed signal, there was very little detectable fluorescence increase in the dendrite and soma under these conditions of stimulation $(n=3)$. This is consistent with the hypothesis that impulse generation is required to produce significant $\mathrm{Ca}^{2+}$ entry from activation of voltage-gated $\mathrm{Ca}^{2+}$ channels in these neurons.

From these results we conclude that, even under the nonvoltage-clamp conditions used here, the measured fluorescence increases in the cilia were caused entirely by $\mathrm{Ca}^{2+}$ entry through CNG channels.

\section{DISCUSSION}

In this study we have shown the existence and properties of $\mathrm{Ca}^{2+}$ transients in individual olfactory cilia caused by the activation of CNG channels. Several main findings emerge from the current work: (1) the ability to resolve spatially and temporally $\mathrm{Ca}^{2+}$ transients in single olfactory cilia; (2) the demonstration that $\mathrm{Ca}^{2+}$ transients in olfactory cilia are mediated by CNG channels within the cilia and not by backpropagation from the dendrite; (3) the demonstration that $\mathrm{Ca}^{2+}$ transients in the dendrite and soma occur with a temporal delay after stimulus-induced events in cilia; (4) the possibility that $\mathrm{Ca}^{2+}$ transients in all of the cilia of individual cells are equivalent, suggesting equipotentiality in odor transduction; and (5) the likelihood that sites of transduction are distributed throughout the cilium, because $\mathrm{Ca}^{2+}$ signals at distal and proximal sites within a single cilium appeared to be similar.

\section{Calcium imaging of salamander olfactory cilia}

Confocal laser scanning microscopy proved to be an effective method to detect $\mathrm{Ca}^{2+}$ changes in olfactory cilia. The experiments were facilitated by the use of the isolated salamander ORN preparation (Firestein and Werblin, 1989), which shows robust cellular responses on activation of the cAMP second messenger system and has played a significant role in developing a basic model of the second messenger apparatus mediating the detection of odor ligands (Firestein et al., 1991a,b; Lowe and Gold, 1991, 1993b; Zufall et al., 1991a,b; Leinders-Zufall et al., 1996). The present work reveals that salamander ORNs are also advantageous for the analysis of $\mathrm{Ca}^{2+}$ signals in olfactory cilia. Thus, although previous studies have shown cytoplasmic $\mathrm{Ca}^{2+}$ responses 

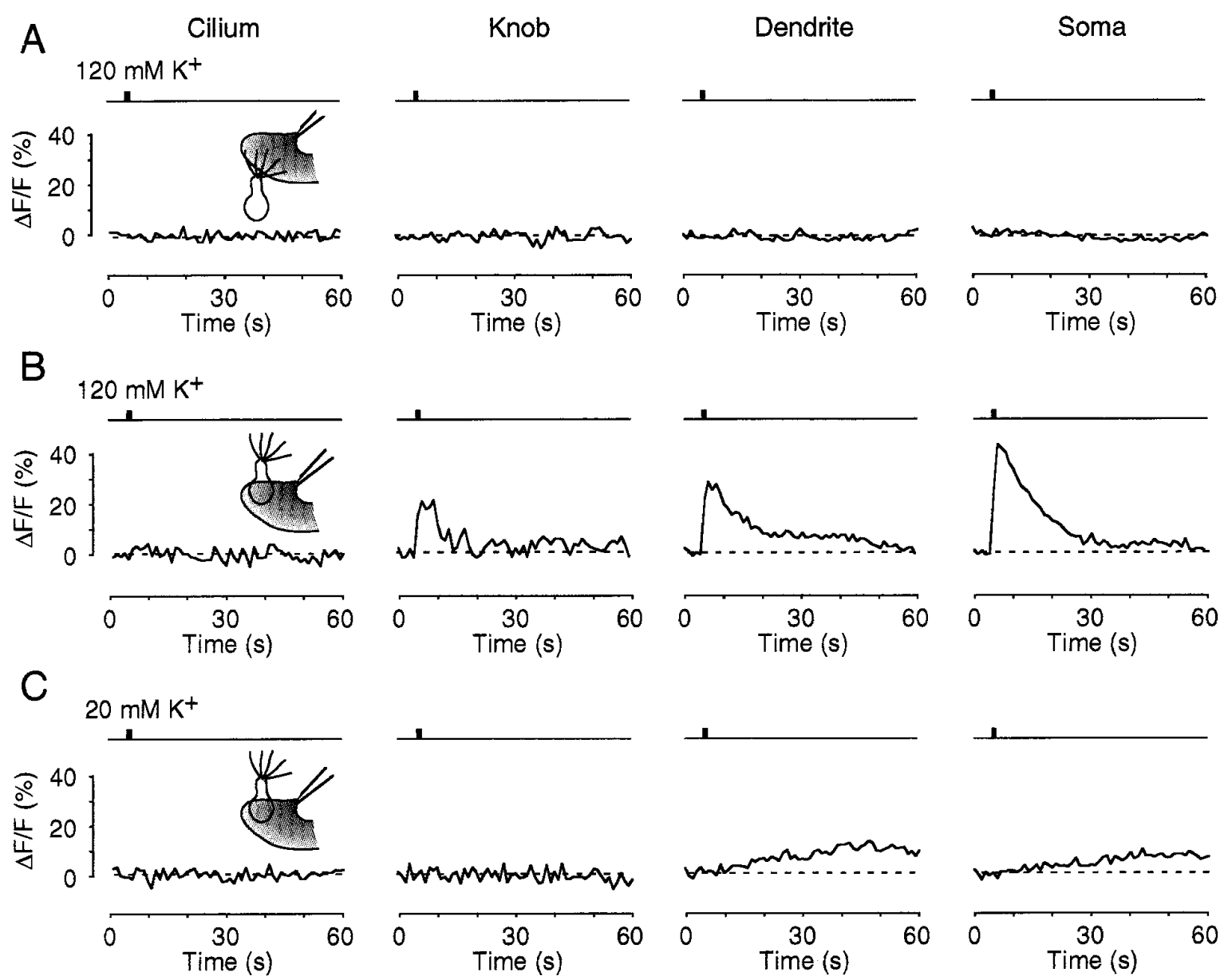

Figure 8. Effect of membrane depolarization induced by elevated external $\mathrm{K}^{+}$on fluorescence levels in various cellular compartments. $A$, Lack of depolarization-induced fluorescence change under conditions in which the $120 \mathrm{~mm} \mathrm{KCl}$ pulse $(1 \mathrm{sec})$ is directed exclusively at the cilia. $B$, Rapid fluorescence increases occur in the soma, dendrite, and, to a smaller extent, in the knob if a $120 \mathrm{mM} \mathrm{KCl}$ pulse is directed at the cell soma. No signal is detectable in the cilia (the results from only one cilium are plotted). The fluorescence increase in the soma decays with a monoexponential time course yielding a time constant of $15.8 \mathrm{sec}$. $C$, Effect of a $20 \mathrm{~mm} \mathrm{KCl}$ pulse $(1 \mathrm{sec})$ directed at the cell soma. There is no measurable fluorescence change in the cilia and the knob, whereas a very small and delayed signal is detectable in the dendrite and soma.

in cell bodies and dendrites of ORNs from rat (Restrepo et al., 1993b; Tareilus et al., 1995), mouse (Sato et al., 1994), man (Restrepo et al., 1993a), catfish (Restrepo et al., 1990; Restrepo and Boyle, 1991), newt (Nakamura et al., 1994), or frog (Sato et al., 1991; Lischka and Schild, 1993), this is the first to demonstrate $\mathrm{Ca}^{2+}$ transients within the ORN cilia.

During the experiments there was neither significant photobleaching nor any evidence of illumination-mediated damage of the cells under our experimental conditions. Fluorescence changes showed full recovery to prestimulation levels. In some cases ORNs were imaged for $>30 \mathrm{~min}$ and $>380$ frames. The indicator dye we used (Fluo-3) does not undergo significant shifts in emission or excitation wavelengths on binding $\mathrm{Ca}^{2+}$, precluding ratio imaging. However, calibration by the use of $\mathrm{Ca}^{2+}$ ionophore and heavy metal chelation as outlined by Kao et al. (1989) resulted in an estimate of $\left[\mathrm{Ca}^{2+}\right]_{\mathrm{i}}$ in unstimulated cilia of $\sim 40 \mathrm{nM}$, which is consistent with previous work that uses ratiometric methods. Tareilus et al. (1995) described resting values of 40-80 nM $\left[\mathrm{Ca}^{2+}\right]_{\mathrm{i}}$ in the soma and knob of rat ORNs, using the methods of Lipp and Niggli (1993), and similar values were found by others using Fura-2 (Sato et al., 1991; Lischka and Schild, 1993; Restrepo et al., 1993b; Nakamura et al., 1994). The relative fluorescence changes $(\Delta F / F)$ of $\sim 20 \%$ in the cilia caused by IBMX pulses (see Table 1) then correspond to a change in $\left[\mathrm{Ca}^{2+}\right]_{\mathrm{i}}$ of $\sim 80 \mathrm{nM}$, assuming a $K_{\mathrm{d}}$ value of $400 \mathrm{~nm}$. Saturation would produce a relative increase of $\sim 110-120 \%$. These high values usually were not reached in our experiments (Table 1), ruling out the possibility that dye saturation posed a significant problem.

\section{Origin of the $\mathrm{Ca}^{2+}$ signals}

The results provide strong evidence that $\mathrm{Ca}^{2+}$ entry through open CNG channels was the primary source of IBMX-stimulated fluorescence increases in the ORN cilia. Olfactory CNG channels are strongly permeable for $\mathrm{Ca}^{2+}$ (Zufall and Firestein, 1993; Frings et al., 1995) and are highly enriched in the ciliary compartment and at the olfactory knob of ORNs (Nakamura and Gold, 1987; Kurahashi and Kaneko, 1991), although they also can be found at a lower density in dendritic and somatic portions of the cells, at least under the conditions of acute isolation of the cells (Zufall et al., 1991a). This result predicts any $\mathrm{Ca}^{2+}$ signal associated with the opening of CNG channels to start at the distal end of the cell and, more specifically, in the cilia. The results of Figure 4 demonstrate that this was the case. In addition, ciliary fluorescence changes depended on $\mathrm{Ca}^{2+}$ entry and were abolished reversibly by 
LY83583 (Fig. 5), a potent blocker of olfactory CNG channels (Leinders-Zufall and Zufall, 1995). Furthermore, the activation time courses of ciliary $\mathrm{Ca}^{2+}$ changes were fully consistent with those of CNG channel responses (Kurahashi, 1990; Firestein et al., 1991a; Leinders-Zufall et al., 1995a). Depolarization of the neuron with high $\mathrm{K}^{+}$solution was not sufficient to elicit measurable $\mathrm{Ca}^{2+}$ changes in the cilia (Fig. 8), ruling out a contribution of voltage-gated $\mathrm{Ca}^{2+}$ channels. Therefore, our results demonstrate that the fluorescence changes detected in the cilia were caused entirely by the activation of CNG channels.

An interesting result was that the $\mathrm{Ca}^{2+}$ responses in the dendrite and soma displayed much longer time courses than those in the cilia and remained sustained for $>1$ min, even after brief stimulation with IBMX (Fig. 4). The distinct time course and complex recovery kinetics of these signals indicate that they were generated by additional mechanisms secondary to $\mathrm{Ca}^{2+}$ entry through $\mathrm{CNG}$ channels. Membrane depolarization by high $\mathrm{K}^{+}$ solution was not sufficient to generate similar $\mathrm{Ca}^{2+}$ changes (Fig. 8). Although the exact mechanisms underlying these dendritic and somatic responses are unknown, preliminary results suggest that $\mathrm{Ca}^{2+}$ stores may be involved. Treatment of the ORNs with thapsigargin, a $\mathrm{Ca}^{2+}$-ATPase inhibitor that promotes $\mathrm{Ca}^{2+}$ release from intracellular compartments, resulted in shortened dendritic responses although no effects were seen on the ciliary $\mathrm{Ca}^{2+}$ transients (Greer et al., 1996). Collectively, the data of Figures 4 and 8 suggest that olfactory cilia function, at least to some extent, as discrete biochemical compartments with $\mathrm{Ca}^{2+}$ dynamics that are relatively independent from those in the rest of the neuron, a situation not unlike that in other small neuronal compartments such as dendritic spines (cf. Woolf and Greer, 1994; Shepherd, 1996).

\section{Implications for transduction and adaptation mechanisms}

The results give added support to the current consensus model of odor detection in which odor receptor activation results in cAMP formation and $\mathrm{CNG}$ channel opening, which ultimately leads to $\mathrm{Ca}^{2+}$ entry into the cilia. Detection of $\mathrm{Ca}^{2+}$ transients in individual cilia is of particular interest with respect to the mechanisms of sensory adaptation in ORNs. Elevated $\left[\mathrm{Ca}^{2+}\right]_{\mathrm{i}}$ governed by the activity of CNG channels plays important roles in feedback control of the sensitivity of olfactory transduction and is involved in a variety of specific regulatory functions such as desensitization during sustained stimulation (Kurahashi and Shibuya, 1990; Zufall et al., 1991b), rapid termination and recovery of the primary odor response (Kurahashi, 1989), and initiation of long-term adaptation (Zufall and Leinders-Zufall, 1997). Although many of the specific mechanisms and consequences triggered by $\mathrm{Ca}^{2+}$ entry remain to be investigated, it is clear from previous work that elevated $\left[\mathrm{Ca}^{2+}\right]_{\mathrm{i}}$ can influence the activity of several molecular components of the cAMP pathway, including adenylyl cyclase (Sklar et al., 1986; Anholt and Rivers, 1990; Jaworski et al., 1995), CNG channels (Zufall et al., 1991b; Kramer and Siegelbaum, 1992; Chen and Yau, 1994; Lynch and Lindemann, 1994), calmodulin-dependent phosphodiesterase (Borisy et al., 1992; Yan et al., 1995), $\mathrm{Ca}^{2+}$-activated $\mathrm{Cl}^{-}$channels (Kleene, 1993; Kurahashi and Yau, 1993; Lowe and Gold, 1993b; Zhainazarov and Ache, 1995), and $\mathrm{Ca}^{2+}$-activated $\mathrm{K}^{+}$channels (Morales et al., 1995).

Our finding that weak stimulation of the CNG channels with low levels of cGMP results in significant $\mathrm{Ca}^{2+}$ elevation in the cilia (Fig. 6) fits well with results from previous work indicating that
cGMP-dependent $\mathrm{Ca}^{2+}$ entry plays a significant role in a longlasting form of odor adaptation (Zufall and Leinders-Zufall, 1997). The main difference between cAMP and cGMP-dependent $\mathrm{Ca}^{2+}$ entry seems to be in the time course of the signals. Activation of the cAMP system leads to more rapid and transient $\mathrm{Ca}^{2+}$ elevations, whereas cGMP signals can maintain elevated $\mathrm{Ca}^{2+}$ levels in olfactory cilia for much longer time spans than the cAMP signals. Furthermore, the cAMP-mediated $\mathrm{Ca}^{2+}$ signals reach higher levels, compared with the responses to physiological (micromolar) concentrations of cGMP. The result that $\left[\mathrm{Ca}^{2+}\right]_{i}$ reaches a plateau during sustained stimulation with $1 \mu \mathrm{M} 8-\mathrm{Br}$ cGMP (Fig. 6) raises the question of how $\mathrm{Ca}^{2+}$ extrusion is being accomplished from olfactory cilia. It is likely that ATP-driven $\mathrm{Ca}^{2+}$ pumps (Lo et al., 1994) and $\mathrm{Na}^{+} / \mathrm{Ca}^{2+}$ exchangers (Jung et al., 1994) described in the apical ORN compartments play a role in these processes.

\section{Conclusion}

The present results establish the concept that activation of the cAMP and cGMP second messenger pathways leads to significant $\mathrm{Ca}^{2+}$ elevation within the olfactory cilia and that $\mathrm{Ca}^{2+}$ entry through $\mathrm{CNG}$ channels plays a predominant role in this process. The protocols developed here should prove useful for analyzing odor-stimulated $\mathrm{Ca}^{2+}$ signals in the cilia; our preliminary results (Zufall et al., 1996) indicate that odor stimulation evokes ciliary $\mathrm{Ca}^{2+}$ signals with spatiotemporal dynamics similar to those obtained in this study by manipulation of the intracellular cyclic nucleotide concentration. Finally, this approach should help to determine the precise functions of $\mathrm{CNG}$ channels expressed in other neurons of the nervous system (cf. Ahmad et al., 1994; Leinders-Zufall et al., 1995b; Kingston et al., 1996; Bradley et al., 1997).

\section{REFERENCES}

Ahmad I, Leinders-Zufall T, Kocsis JD, Shepherd GM, Zufall F, Barnstable CJ (1994) Retinal ganglion cells express a cGMP-gated cation conductance activatable by nitric oxide donors. Neuron 12:155-165.

Anderson PAV, Hamilton KA (1987) Intracellular recordings from isolated salamander olfactory receptor neurons. Neuroscience 21:167-173.

Anholt RRH, Rivers AM (1990) Olfactory transduction: cross-talk between second-messenger systems. Biochemistry 29:4049-4054.

Borisy FF, Ronnett GV, Cunningham AM, Julif D, Beavo J, Snyder SH (1992) Calcium/calmodulin-activated phosphodiesterase expressed in olfactory receptor neurons. J Neurosci 12:915-923.

Bradley J, Zhang Y, Bakin R, Lester HA, Ronnett GV, Zinn K (1997) Functional expression of the heteromeric "olfactory" cyclic nucleotidegated channel in the hippocampus: a potential effector of synaptic plasticity in brain neurons. J Neurosci 17:1993-2005.

Breer H (1993) Second messenger signalling in olfaction. In: Ciba Foundation Symposium 179. The molecular basis of smell and taste transduction, pp 97-114. Chichester, UK: Wiley.

Breer H, Klemm T, Boekhoff I (1992) Nitric oxide-mediated formation of cyclic GMP in the olfactory system. NeuroReport 3:1030-1032.

Brunet LJ, Gold GH, Ngai J (1996) General anosmia caused by a targeted disruption of the mouse olfactory cyclic nucleotide-gated cation channel. Neuron 17:681-693.

Chen T-Y, Yau K-W (1994) Direct modulation by $\mathrm{Ca}^{2+}$-calmodulin of cyclic nucleotide-activated channel of rat olfactory receptor neurons. Nature 368:545-548.

Firestein S, Werblin F (1989) Odor-induced membrane currents in vertebrate olfactory receptor neurons. Science 244:79-82.

Firestein S, Darrow B, Shepherd GM (1991a) Activation of the sensory current in salamander olfactory receptor neurons depends on a G-protein-mediated cAMP second messenger system. Neuron 6:825-835.

Firestein S, Zufall F, Shepherd GM (1991b) Single odor-sensitive chan- 
nels in olfactory receptor neurons are also gated by cyclic nucleotides. J Neurosci 11:3565-3572.

Frings S, Lynch JW, Lindemann B (1992) Properties of cyclic nucleotidegated channels mediating olfactory transduction. J Gen Physiol 100:45-67.

Frings S, Seifert R, Godde M, Kaupp UB (1995) Profoundly different calcium permeation and blockage determine the specific function of distinct cyclic nucleotide-gated channels. Neuron 15:169-179.

Greer CA, Rand MN, Leinders-Zufall T, Shepherd GM, Zufall F (1996) Role of $\mathrm{IP}_{3}$-sensitive calcium stores in salamander olfactory receptor neurons. Chem Senses 21:A609.

Ingi T, Ronnett GV (1995) Direct demonstration of a physiological role for carbon monoxide in olfactory receptor neurons. J Neurosci 15:8214-8222.

Jaworsky DE, Matsuzaki O, Borisy FF, Ronnett GV (1995) Calcium modulates the rapid kinetics of the odorant-induced cyclic AMP signal in rat olfactory cilia. J Neurosci 15:310-318.

Jung A, Lischka FW, Engel J, Schild D (1994) Sodium/calcium exchanger in olfactory receptor neurones of Xenopus laevis. NeuroReport 5:1741-1744.

Kao JPY, Harootunian AT, Tsien RY (1989) Photochemically generated cytosolic calcium pulses and their detection by Fluo-3. J Biol Chem 264:8179-8184.

Kingston PA, Zufall F, Barnstable CJ (1996) Rat hippocampal neurons express genes for both rod retinal and olfactory cyclic nucleotide-gated channels: novel targets for cAMP/cGMP function. Proc Natl Acad Sci USA 93:10440-10445.

Kleene SJ (1993) Origin of the chloride current in olfactory transduction. Neuron 11:123-132.

Kramer RH, Siegelbaum SA (1992) Intracellular $\mathrm{Ca}^{2+}$ regulates the sensitivity of cyclic nucleotide-gated channels in olfactory receptor neurons. Neuron 9:897-906.

Kurahashi T (1989) Activation by odorants of a cation-selective conductance in the olfactory receptor cell isolated from the newt. J Physiol (Lond) 419:177-192.

Kurahashi T (1990) The response induced by intracellular cyclic AMP in isolated olfactory receptor cells of the newt. J Physiol (Lond) 430:355-371.

Kurahashi T, Kaneko A (1991) High density cAMP-gated channels at the ciliary membrane in the olfactory receptor cell. NeuroReport 2:5-8.

Kurahashi T, Menini A (1997) Mechanism of odorant adaptation in the olfactory receptor cell. Nature 385:725-729.

Kurahashi T, Shibuya T (1990) $\mathrm{Ca}^{2+}$-dependent adaptive properties in the solitary olfactory receptor cells of the newt. Brain Res 515:261-268.

Kurahashi T, Yau K-W (1993) Co-existence of cationic and chloride components in odorant-induced current of vertebrate olfactory receptor cells. Nature 363:71-74.

Lancet D (1986) Vertebrate olfactory reception. Annu Rev Neurosci 9:329-355.

Leinders-Zufall T, Zufall F (1995) Block of cyclic nucleotide-gated channels in salamander olfactory receptor neurons by the guanylyl cyclase inhibitor LY83583. J Neurophysiol 74:2759-2762.

Leinders-Zufall T, Rand MN, Waxman SG, Kocsis JD (1994) Differential role of two $\mathrm{Ca}^{2+}$-permeable non-NMDA glutamate channels in rat retinal ganglion cells: kainate-induced cytoplasmic and nuclear $\mathrm{Ca}^{2+}$ signals. J Neurophysiol 72:2503-2516.

Leinders-Zufall T, Shepherd GM, Zufall F (1995a) Regulation of cyclic nucleotide-gated channels and membrane excitability in olfactory receptor cells by carbon monoxide. J Neurophysiol 74:1498-1508.

Leinders-Zufall T, Rosenboom H, Barnstable CJ, Shepherd GM, Zufall F (1995b) A calcium-permeable cGMP-activated cation conductance in hippocampal neurons. NeuroReport 6:1761-1765.

Leinders-Zufall T, Shepherd GM, Zufall F (1996) Modulation by cyclic GMP of the odor sensitivity of vertebrate olfactory receptor cells. Proc R Soc Lond [Biol] 263:803-811.

Lipp P, Niggli E (1993) Ratiometric confocal $\mathrm{Ca}^{2+}$-measurements with visible wavelength indicators in isolated cardiac myocytes. Cell Calcium 14:359-372.

Lischka FW, Schild D (1993) Standing calcium gradients in olfactory receptor neurons can be abolished by amiloride or ruthenium red. J Gen Physiol 102:817-831.

Lo YH, Bradley TM, Rhoads DE (1994) High-affinity $\mathrm{Ca}^{2+}, \mathrm{Mg}^{2+}$. ATPase in plasma membrane-rich preparations from olfactory epithelium of Atlantic salmon. Biochim Biophys Acta 1192:153-158.

Lowe G, Gold GH (1991) The spatial distributions of odorant sensitivity and odorant-induced currents in salamander olfactory receptor cells. J Physiol (Lond) 442:147-168.

Lowe G, Gold GH (1993a) Contribution of the ciliary cyclic nucleotidegated conductance to olfactory transduction in the salamander. J Physiol (Lond) 462:175-196.

Lowe G, Gold GH (1993b) Nonlinear amplification by calciumdependent chloride channels in olfactory receptor cells. Nature 366:283-286.

Lynch JW, Lindemann B (1994) Cyclic nucleotide-gated channels of rat olfactory receptor cells: divalent cations control the sensitivity of cAMP. J Gen Physiol 103:87-106.

Menco BPM (1994) Ultrastructural aspects of olfactory transduction and perireceptor events. Semin Cell Biol 5:11-24.

Menco BPM, Bruch RC, Dau B, Danho W (1992) Ultrastructural localization of olfactory transduction components: the G-protein subunit $\mathrm{G}_{\mathrm{olf} \alpha}$ and type III adenylyl cyclase. Neuron 8:441-453.

Minta A, Kao JPY, Tsien RY (1989) Fluorescent indicators for cytosolic calcium based on rhodamine and fluorescein chromophores. J Biol Chem 264:8171-8179.

Morales B, Labarca P, Bacigalupo J (1995) A ciliary $\mathrm{K}^{+}$conductance sensitive to charibdotoxin underlies inhibitory responses in toad olfactory receptor neurons. FEBS Lett 359:41-44.

Nakamura T, Gold GH (1987) A cyclic-nucleotide-gated conductance in olfactory receptor cilia. Nature 325:442-444.

Nakamura T, Tsuru K, Miyamoto S (1994) Regulation of $\mathrm{Ca}^{2+}$ concentration by second messengers in newt olfactory receptor cell. Neurosci Lett 171:197-200.

Reed RR (1992) Signaling pathways in odorant detection. Neuron 8:205-209.

Restrepo D, Boyle AG (1991) Stimulation of olfactory receptors alters regulation of $\left[\mathrm{Ca}^{2+}\right]_{\mathrm{i}}$ in olfactory neurons of the catfish (Ictalurus punctatus). J Membr Biol 120:223-232.

Restrepo D, Miyamoto T, Bryant BP, Teeter JH (1990) Odor stimuli trigger influx of calcium into olfactory neurons of the channel catfish. Science 249:1166-1168.

Restrepo D, Okada Y, Teeter JH, Lowry LD, Cowart B, Brand JG (1993a) Human olfactory neurons respond to odor stimuli with an increase in cytoplasmic $\mathrm{Ca}^{2+}$. Biophys J 64:1961-1966.

Restrepo D, Okada Y, Teeter JH (1993b) Odorant-regulated $\mathrm{Ca}^{2+}$ gradients in rat olfactory neurons. J Gen Physiol 102:907-924.

Restrepo D, Teeter JH, Schild D (1996) Second messenger signaling in olfactory transduction. J Neurobiol 30:37-48.

Sato T, Hirono J, Tonoike M, Takebayashi M (1991) Two types of increases in free $\mathrm{Ca}^{2+}$ evoked by odor in isolated frog olfactory receptor neurons. NeuroReport 2:229-232.

Sato T, Hirono J, Tonoike M, Takebayashi M (1994) Tuning specificities to aliphatic odorants in mouse olfactory receptor neurons and their local distribution. J Neurophysiol 72:2980-2989.

Schild D, Jung A, Schultens HA (1994) Localization of calcium entry through calcium channels in olfactory receptor neurones using a laser scanning microscope and the calcium indicator dyes Fluo-3 and Furared. Cell Calcium 15:341-348.

Schild D, Lischka FW, Restrepo D (1995) $\mathrm{InsP}_{3}$ causes an increase in apical $\left[\mathrm{Ca}^{2+}\right]_{i}$ by activating two distinct current components in vertebrate olfactory cells. J Neurophysiol 73:862-866.

Shepherd GM (1996) The dendritic spine: a multifunctional integrative unit. J Neurophysiol 75:2197-2210.

Simmons PA, Rafols JA, Getchell TV (1981) Ultrastructural changes in olfactory receptor neurons following olfactory nerve section. J Comp Neurol 197:237-257.

Sklar PB, Anholt RRH, Snyder SH (1986) The odorant-sensitive adenylate cyclase of olfactory receptor cells. J Biol Chem 261:15538-15543.

Tareilus E, Noé J, Breer H (1995) Calcium signals in olfactory neurons. Biochim Biophys Acta 1269:129-138.

Thomas AP, Delaville F (1991) The use of fluorescent indicators for measurements of cytosolic-free calcium concentration in cell populations and single cells. In: Cellular calcium. A practical approach (McCormack JG, Cobbold PH, eds), pp 1-54. New York: Oxford UP.

Verma A, Hirsch DJ, Glatt CE, Ronnett GV, Snyder SH (1993) Carbon monoxide: a putative neural messenger. Science 259:381-384.

Woolf TB, Greer CA (1994) Local communication within dendritic spines: models of second messenger diffusion in granule cell spines of the mammalian olfactory bulb. Synapse 17:247-267.

Yan C, Zhao AZ, Bentley JK, Loughney K, Ferguson K, Beavo JA (1995) 
Molecular cloning and characterization of a calmodulin-dependent phosphodiesterase enriched in olfactory sensory neurons. Proc Natl Acad Sci USA 92:9677-9681.

Zhainazarov AB, Ache BW (1995) Odor-induced currents in Xenopus olfactory receptor cells measured with perforated-patch recording. J Neurophysiol 74:479-483.

Zufall F, Firestein S (1993) Divalent cations block the cyclic nucleotidegated channel of olfactory receptor neurons. J Neurophysiol 69:1758-1768.

Zufall F, Leinders-Zufall T (1997) Identification of a long-lasting form of odor adaptation that depends on the carbon monoxide/cGMP second messenger system. J Neurosci 17:2703-2712.
Zufall F, Firestein S, Shepherd GM (1991a) Analysis of single cyclic nucleotide-gated channels in olfactory receptor cells. J Neurosci 11:3573-3580.

Zufall F, Shepherd GM, Firestein S (1991b) Inhibition of the olfactory cyclic nucleotide-gated ion channel by intracellular calcium. Proc R Soc Lond [Biol] 246:225-230.

Zufall F, Firestein S, Shepherd GM (1994) Cyclic nucleotide-gated channels and sensory transduction in olfactory receptor neurons. Annu Rev Biophys Biomol Struct 23:577-607.

Zufall F, Leinders-Zufall T, Rand MN, Shepherd GM, Greer CA (1996) Odor-stimulated calcium signaling in cilia and dendrites of olfactory receptor neurons. Soc Neurosci Abstr 22:259. 